\title{
Categorizing factors of adherence to parenteral treatment in growth hormone deficiencies and hemophilia:What should be the targets for future research?
}

This article was published in the following Dove Press journal:

Patient Preference and Adherence

\author{
Serge Sultan ${ }^{1-3}$ \\ Mira El-Hourani ${ }^{3}$ \\ Émélie Rondeau' \\ Nicolas Garnier ${ }^{4}$ \\ 'Department of Hematology- \\ Oncology, CHU Sainte-Justine, \\ Montréal, Québec, Canada; \\ ${ }^{2}$ Department of Pediatrics, Université \\ de Montréal, Montréal, Québec, \\ Canada; ${ }^{3}$ Department of Psychology, \\ Université de Montréal, Montréal, \\ Québec, Canada; ${ }^{4}$ Pfizer Canada Inc, \\ Rare Disease Unit, Medical Affairs, \\ Kirkland, Québec, Canada
}

\begin{abstract}
Adherence to treatment regimens in growth hormone dysregulations and hemophilia is related to better outcome and fewer complications over time. Subcutaneous growth hormone injection and intravenous blood factor replacement therapies are parenteral treatments with a comparable regimen calling for similar behavioral processes. Although we have lists of possible factors influencing adherence in these conditions, the evidence is scattered. The objective of this study was to systematically review empirical studies linking factors of adherence with measures of adherence. To categorize the factors, we used a taxonomy from the diabetes literature. We used four major electronic databases to identify articles. We synthesized 27 articles dated 2011-2017 corresponding to inclusion criteria. Results showed a consistent proportion of $20 \%-25 \%$ participants with adherent issues. Strong arguments pointed to the transition to selfcare in pediatrics as a vulnerability period ( $7 / 27$ reports). We found the domains of individual factors ( $<30 \%$ reports), relational factors $(<13 \%)$, health care $(<30 \%)$, to be understudied in comparison with that of demographic or clinical context $(>74 \%)$, and practical issues $(>37 \%)$. The results suggest that future research should focus on modifiable factors of adherence, with appropriate measurement and intervention strategies. One central methodological limitation of reviewed reports was the lack of longitudinal designs, and the quasi absence of behavioral trial targeting modifiable factors of adherence. A new research agenda should be set in these rare diseases as higher adherence should translate into improved outcome and better quality of life for patients and their families.
\end{abstract}

Keywords: adherence, factors, predictors, classification, growth hormone, hemophilia

\section{Introduction}

Growth hormone (GH) dysregulations including growth hormone deficiencies (GHDs) and hemophilia are rare diseases affecting children and adults (prevalence 1-25/100,000 in childhood). They are non-curable diseases, generally diagnosed early and treated through the life span with replacement therapy designed to provide long-term benefits and avoid important health complications. In GHD for instance, poor adherence can undermine important health outcomes such as stature and height velocity. ${ }^{1,2}$ Two-year follow-ups showed that children who missed more than half of their monthly dose had lower annual growth $(6 \mathrm{~cm} /$ year $)$ than those who missed less than half of their doses ( $9 \mathrm{~cm} /$ year). ${ }^{3}$ In severe hemophilia, prophylactic replacement therapy has been the most effective treatment approach to prevent bleeding and maintain joint function. In this condition, recent studies demonstrate that adherence is associated with
Department of Hematology-Oncology,

CHU Sainte-Justine, 3175 Chemin de

la Côte Sainte-Catherine, Montréal,

QC H3T IC5, Canada

Tel +I 5 I4 345493 I extn 7068

Email serge.sultan@umontreal.ca 
reduced chronic pain, improved physical functioning, and less orthopedic surgery., ${ }^{4,5}$ However, adherent treatment behaviors have rarely been studied systematically, and factors of adherence are still unclear in these clinical contexts. The common characteristics of timeline, and the consistent role of treatment behaviors involving injection/infusion including a third party in childhood, suggest that behaviors may be approached similarly in these conditions. In addition, comparisons may be drawn with a far more prevalent condition (type 1 diabetes 300/100,000), where behavioral research is advanced.

GH therapy is indicated in a variety of conditions such as GHD. In this case, the treatment regimen typically includes daily injections of recombinent human $\mathrm{GH}$ (rhGH) until completion of linear growth. In this field, studies have mainly used indirect methods to assess treatment behavior. ${ }^{6}$ The prevalence of non-adherence in pediatric populations was found to vary greatly from $5 \%$ to $82 \%$, depending on the methods and definitions used. The most frequently used cutoff point to define non-adherence is one or more injections missed/week. ${ }^{6}$ Estimates based on prescription data indicate that, of 75 children followed for 12 months, 39\% and 23\% missed more than one and two injections/week, respectively. ${ }^{7,8}$ Similarly, prophylaxis regimen is essential in severe hemophilia. Although prophylaxis may be personalized, the regimen refers typically to two protocols (Malmö and Utrecht) requiring that factors be infused $3 \times /$ week for hemophilia A and $2 \times /$ week for hemophilia B. Reported levels of adherence to prophylaxis in severe hemophilia have ranged from $44 \%$ to $87 \%$ and non-adherence or suboptimal adherence from $13 \%$ to $56 \%$. ${ }^{9}$ A recent method based on expert consensus has helped define adherence, suboptimal adherence, and non-adherence to prophylaxis in relation to missed infusions, dose changes, and timing changes. ${ }^{10}$ With this algorithm, adherence to prophylaxis treatment was defined as a maximum $15 \%$ infusions missed, maximum $10 \%$ deviation in dose (IU), and maximum $30 \%$ deviation in timing (hour). In contrast, non-adherence was defined as more than $25 \%$ infusion missed or $>25 \%$ deviation in dose, or a combination of both. In both the conditions, nonadherence is thus mainly operationalized through an estimate of missed injections, although other aspects such as dosage are also considered. Frequencies of non-adherence vary greatly according to sample, study, and measures taken.

A review of factor of adherence to GH therapy ${ }^{6}$ concluded that there was conflicting evidence from different studies, which demonstrated an association or lack thereof between adherence and age, socioeconomic status, duration of treatment, level of understanding, injection giver, practical difficulty with injections, type of device used, and choice of device. The reasons for these discrepancies remain unclear. These may be due to differences in methodology, sample size, and the population assessed. The factors associated with poor adherence to GH therapy in pediatric patients include heterogeneous aspects such as being adolescent, discomfort with injections, low level of understanding of treatment, and ethnicity. Another review in hemophilia identified the motivators and barriers of adherence. ${ }^{11}$ Motivators for a high adherence were experiencing symptoms, holding a positive belief of necessity of treatment, and a good relationship with the health care provider. Barriers were infrequent or absence of symptoms and older age. The authors concluded to the importance of developing an age-specific approach to adherence and adherence factors. Both the reviews were thus exclusively empirically driven and did not provide a taxonomy of factors, an aspect which is essential for future research recommendation and intervention. This contrasts with the results obtained in type 1 diabetes where the authors have proposed classifications of factors that help comparisons of adherence determinants and intervention.

Two reviews of real-world studies in diabetes suggest that the main factor domains of adherence to insulin injection may be summarized in demographic and clinical context, individual, social environment, practical, and health care issues. ${ }^{12,13}$ Examples for demographic and clinical context are sex or older age. ${ }^{12}$ For individual factors, an example is perceived treatment efficacy: patients are more likely to adhere if they have a tangible sense that the injection will contribute to some positive and not too remote outcome. ${ }^{14}$ For social environment, normative pressure and social influence are examples. ${ }^{12,13}$ An example of practical factor refers to the type of delivery device, with the use of pens consistently yielding higher levels of adherence than syringe in all reviewed studies. ${ }^{12}$ This is also underlined by several large-scale surveys suggesting that practical barriers are central. ${ }^{14,15}$ As for health care issues, studies demonstrate the role of health care provider trust, a sense of concordance with the physician and a perception of a good quality of communication as perceived by patients and families. ${ }^{13}$ These broad categories are further defined in Table 1. They may constitute a simple comparator to evaluate the current state of research in $\mathrm{GH}$ and hemophilia prophylaxis treatment.

\section{Objective}

The purpose of this work was to identify the categories of factors of adherent treatment behavior in patients treated with $\mathrm{GH}$ or those with severe hemophilia treated with prophylaxis. 
Table I Taxonomy of factors of adherence identified in diabetes research and expected to be found in growth hormone-treated conditions and hemophilia

\begin{tabular}{|c|c|}
\hline Domains & Factors or predictors \\
\hline $\begin{array}{l}\text { Demographic and clinical } \\
\text { context } \\
\text { (non-modifiable) }\end{array}$ & $\begin{array}{l}\text { Diagnosis, illness severity, symptoms, treatment outcomes } \\
\text { Illness duration } \\
\text { Age, maturity, pubertal status, or adolescent phase } \\
\text { Injector/infuser (parent vs child, confounded with age) }\end{array}$ \\
\hline $\begin{array}{l}\text { Injector or infuser } \\
\text { (patients or parents) }\end{array}$ & $\begin{array}{l}\text { Knowledge, understanding (disease, treatment) } \\
\text { Know-how (treatment skills) } \\
\text { Feeling capable, controllability, self-efficacy } \\
\text { Positive beliefs: treatment necessity, expected benefits } \\
\text { Negative beliefs: treatment concern, expected side effects, negative consequences } \\
\text { Psychological barriers: psychological issues, negative effects, distress }\end{array}$ \\
\hline Social environment & $\begin{array}{l}\text { Child-parent relationship quality } \\
\text { Parental monitoring and supervision } \\
\text { Parental involvement } \\
\text { Promoting transition to self-care } \\
\text { Social norms } \\
\text { Social and peer support } \\
\text { Social stigma }\end{array}$ \\
\hline Practical issues & $\begin{array}{l}\text { Barriers such as issues in treatment availability, tight schedule, etc. } \\
\text { Delivery device: burden, complexity, convenience } \\
\text { Financial cost to the family }\end{array}$ \\
\hline Health care & $\begin{array}{l}\text { Trust with health care provider } \\
\text { Good relationship with provider } \\
\text { Transition program } \\
\text { Type of care: rural vs urban, country specificities }\end{array}$ \\
\hline
\end{tabular}

We wished to identify extant empirical data and coherently group the factors of adherence according to categories emerging from the diabetes literature (Table 1). The specifications of this literature review are the following. Patients: children, adolescents, and adults. Conditions: any condition treated by rhGH, or hemophilia A or B treated with prophylaxis blood factor replacement therapy. Adherence measure: any explicit measure of adherence. Association: any estimate of association or difference, such as $\mathrm{r}, \mathrm{d}$, $\mathrm{t}$, or beta for quantitative and frequency or presence for qualitative reports. Factors: any aspect for which an estimate of association, difference, frequency, or presence was mentioned and that was interpreted as an explanatory factor of adherence.

\section{Method}

\section{Search strategy}

For both the domains, we used a similar systematic search strategy applied to common electronic databases. The electronic databases PubMed, Embase, CINAHL, and PsycINFO were searched for eligible studies. Given that previous reviews examined adherence factors up to 2011 , we focused on the time period January 2011 to December 2017. The keywords applied to title and abstract included both 1) terms concerning GH treatment (or hemophilia) and 2) terms concerning adherence. For GH-treated conditions, the syntax was: (growth hormone) AND (adherence OR compliance OR nonadherence OR noncompliance OR non-adherence OR non-compliance OR persistence OR concordance). For hemophilia, the first term was replaced by (hemophil* OR haemophil*). Limits were set in all searches to human studies and English language full-texts. To ensure inclusion of gray literature, we set no limits on the type of document retrieved (congress abstracts, theses, etc). We tracked references and related articles to minimize the risks of false negatives. A preliminary selection was performed by two reviewers (SS and $\mathrm{MEH}$ ) on the basis of the abstract in order to screen for irrelevant items. In case of doubt of one reviewer, full-texts were retrieved and examined. Following this preliminary selection, full-text were read, selected for relevance, and information was extracted for relevant items. The inter-rater agreement for full-text relevance was $90 \%$ and in the rare cases where reviewers disagreed the full-text was discussed until a consensus was reached.

\section{Assessment of methodological quality}

To avoid an excessive rate of exclusion on the basis of strict quality criteria, we did not use a formal inventory such as Cochrane or STROBE statements. ${ }^{16,17}$ However, retrieved 
studies were discussed on ad hoc criteria, particularly whether modifiable factors preceded the outcome (see "Discussion" section).

\section{Data extraction and management}

The following data items were extracted in an Excel spreadsheet: author, year of publication, sample origin/country, clinical condition, sample demographics and clinical features, primary/secondary objective, data collection design (eg, quasi-experimental trial, cross-sectional survey), statistical design, adherence measure, factors of adherence significant, factors of adherence nonsignificant, factors of adherence suggested by authors, and funding source. The same two reviewers (SS and MEH) extracted data independently, and discrepancies were resolved based on the contents of the articles.

\section{Summary measures}

To summarize findings on factors, we compared the number of studies addressing each group of adherence factors from Table 1. We also produced a narrative synthesis on unstudied factors suggested by authors as explanatory factors in the discussion sections of the reports.

\section{Results: GH-treated conditions Study selection}

The selection process is presented in a flow diagram (Figure S1). The initial search resulted in 423 hits (PubMed: 99, Embase: 268, CINAHL: 52, PsycINFO: 4). After removing 131 duplicates, 292 items were screened on the basis of their abstract. In case of the absence of abstract, full-text was retrieved; 264 were excluded following this pass (eg, adherence was not studied in 123 , factors were not investigated in 39). Then, 28 were thus selected for full-text analysis and six of these were excluded for various reasons (eg, four did not inquire factors). Finally, 22 reports were matched to the inclusion criteria and relevant to the research question. Eleven reports were full research articles published in peer-reviewed journals and eleven were conference abstracts. However, due to limited details, we could not include abstracts in the full review. The final set of eleven full research articles is summarized in Table $2 .{ }^{18-28}$

\section{Study description}

Nine of the eleven studies were from one country and two included more than one country. Most studies were performed in Europe (6/11) and only two samples were partly from the USA.

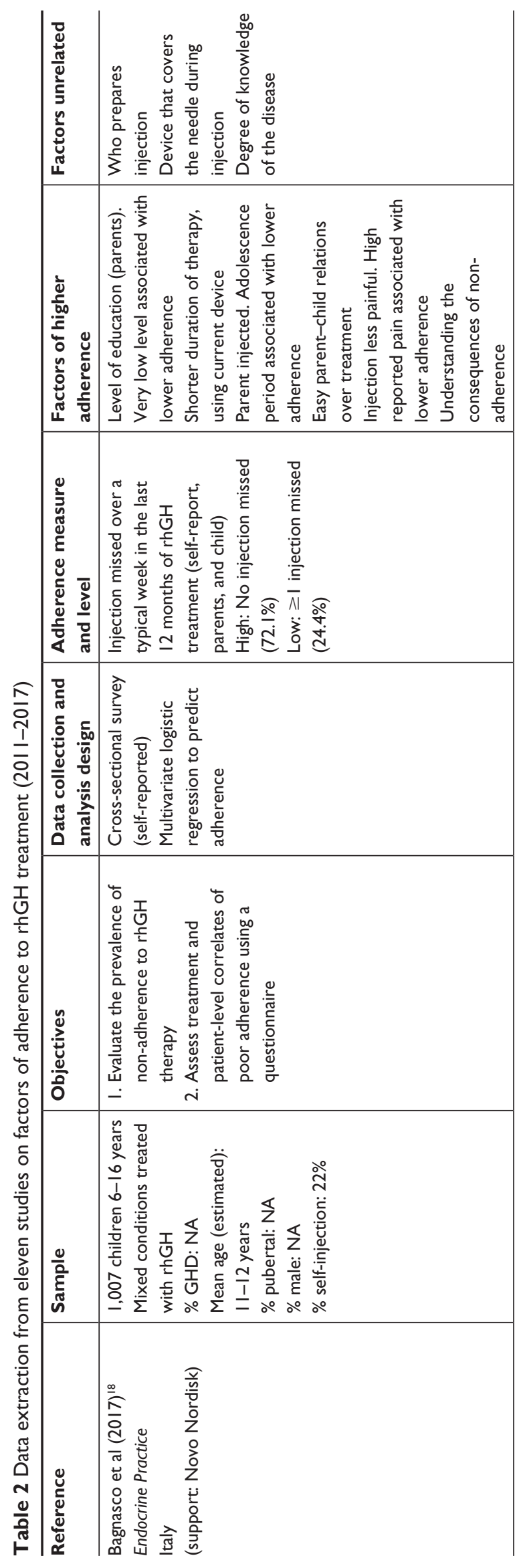




\begin{tabular}{|c|c|c|c|}
\hline & 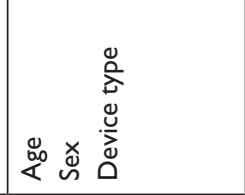 & 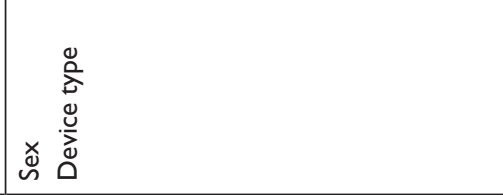 & 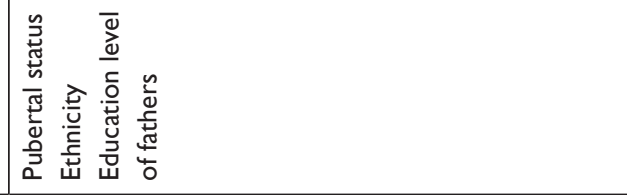 \\
\hline \multirow[t]{6}{*}{ 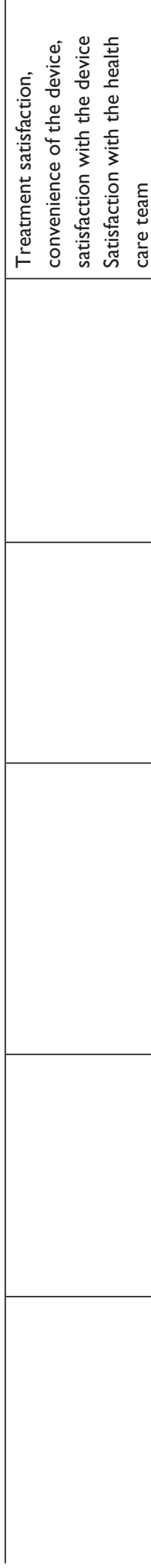 } & 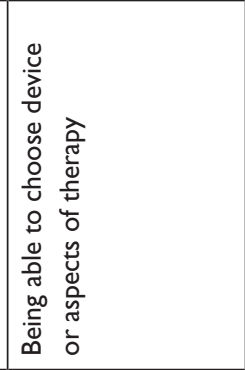 & 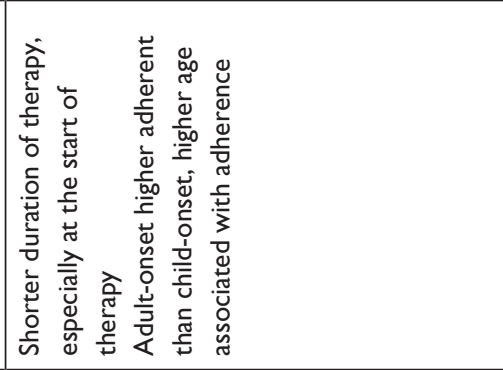 & 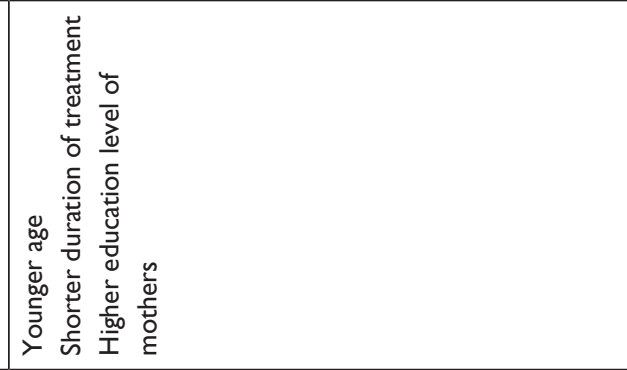 \\
\hline & 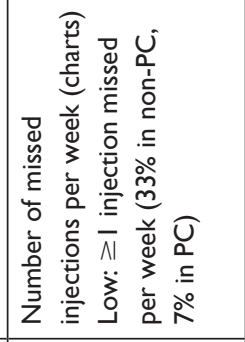 & 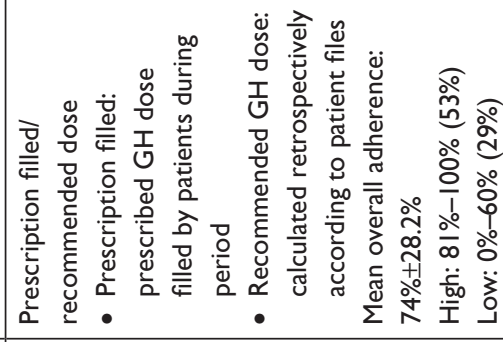 & 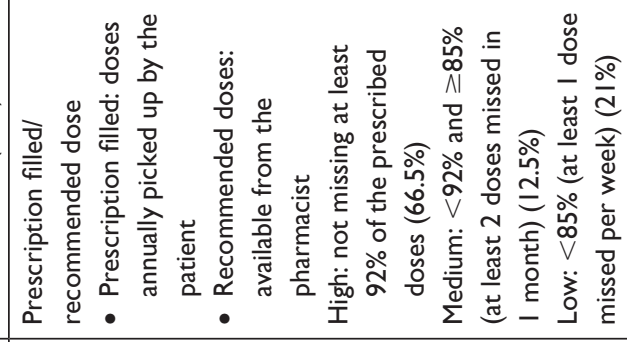 \\
\hline & 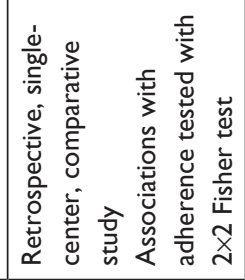 & 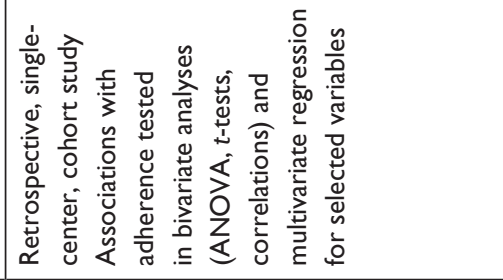 & 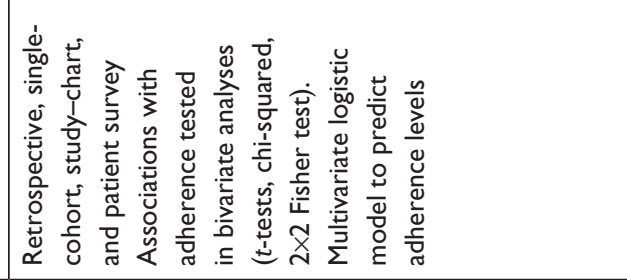 \\
\hline & 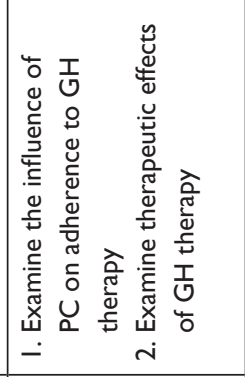 & 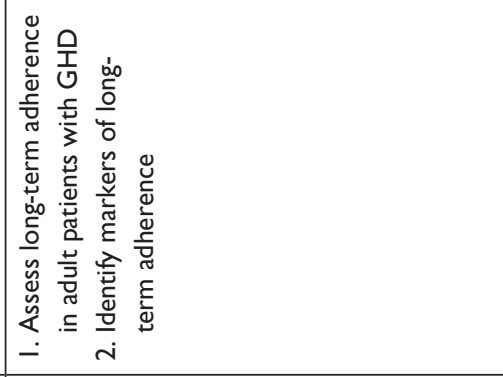 & 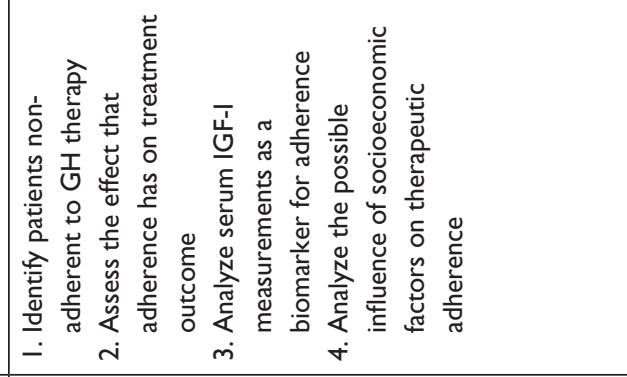 \\
\hline & 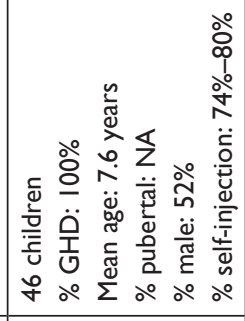 & 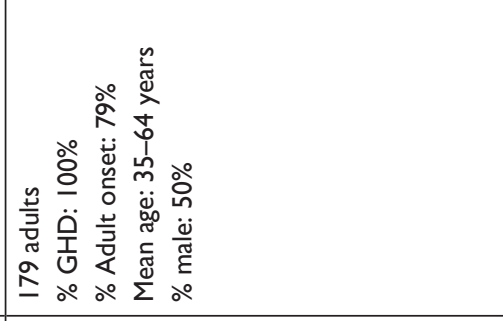 & 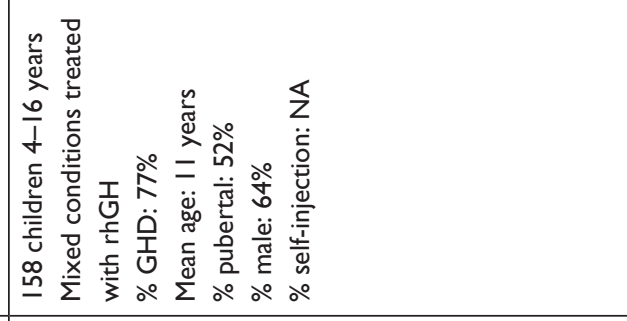 \\
\hline & 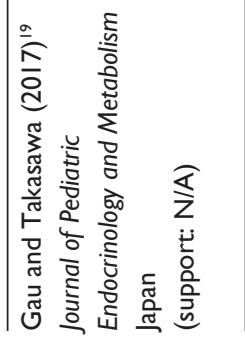 & 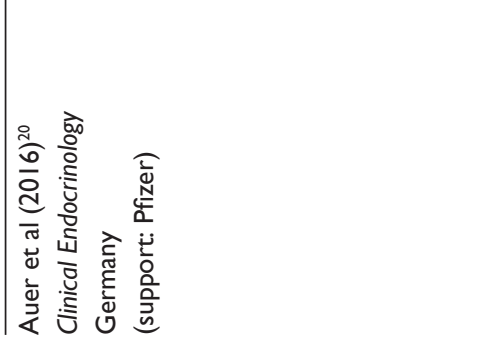 & 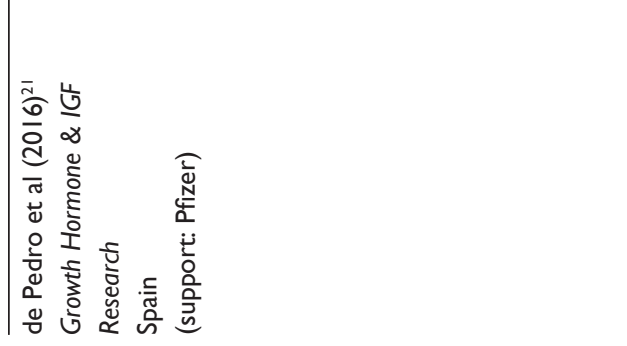 \\
\hline
\end{tabular}




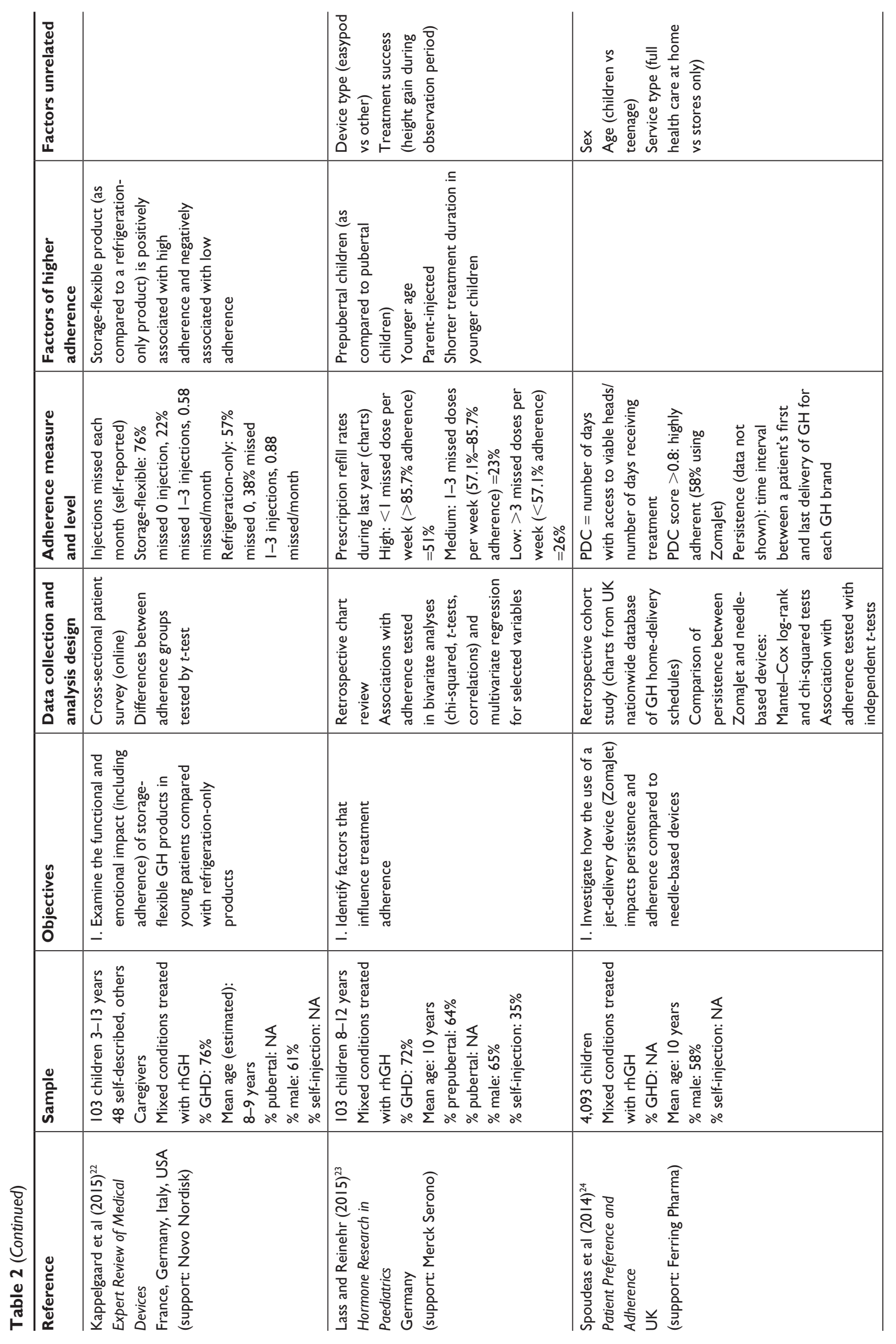




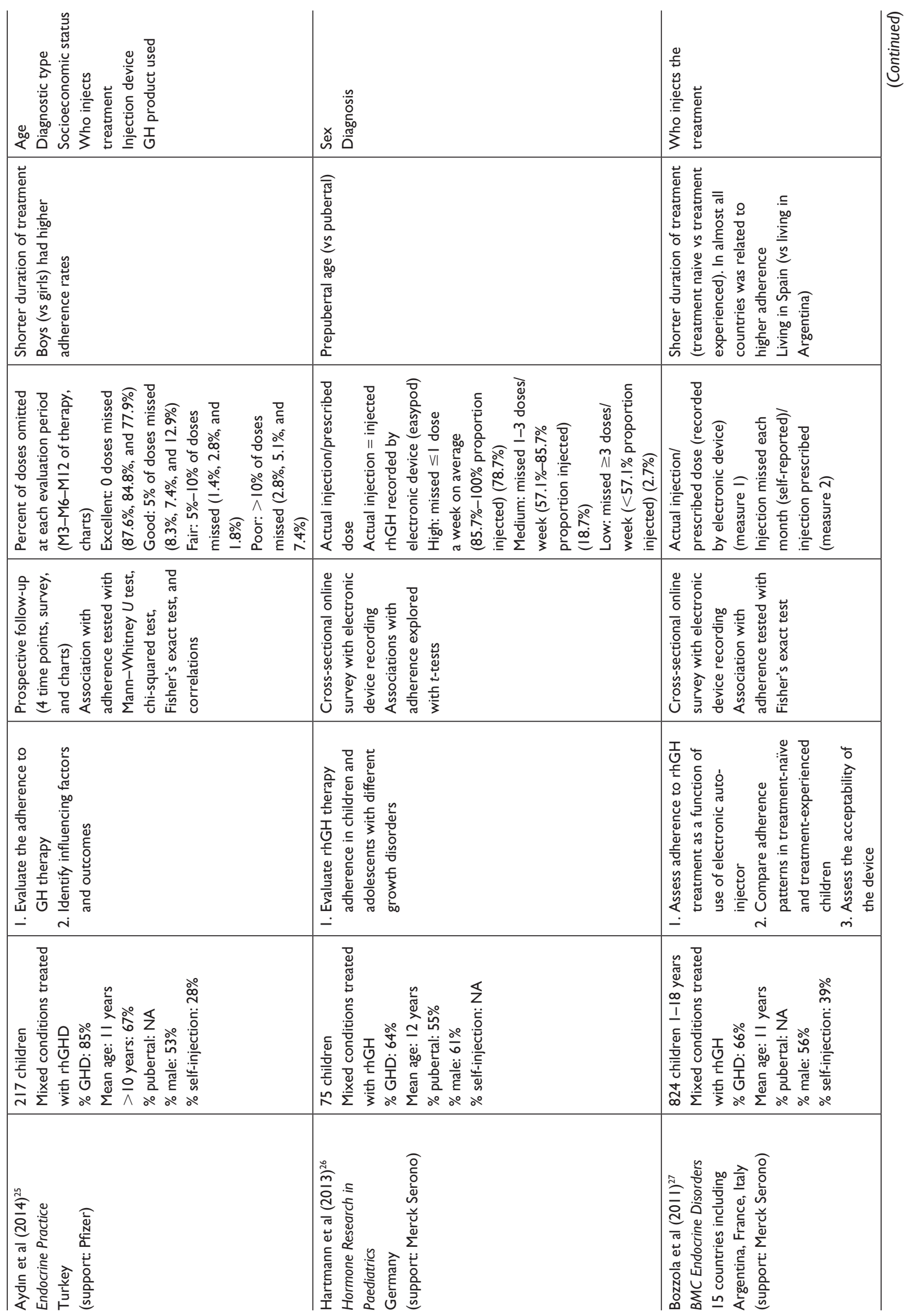




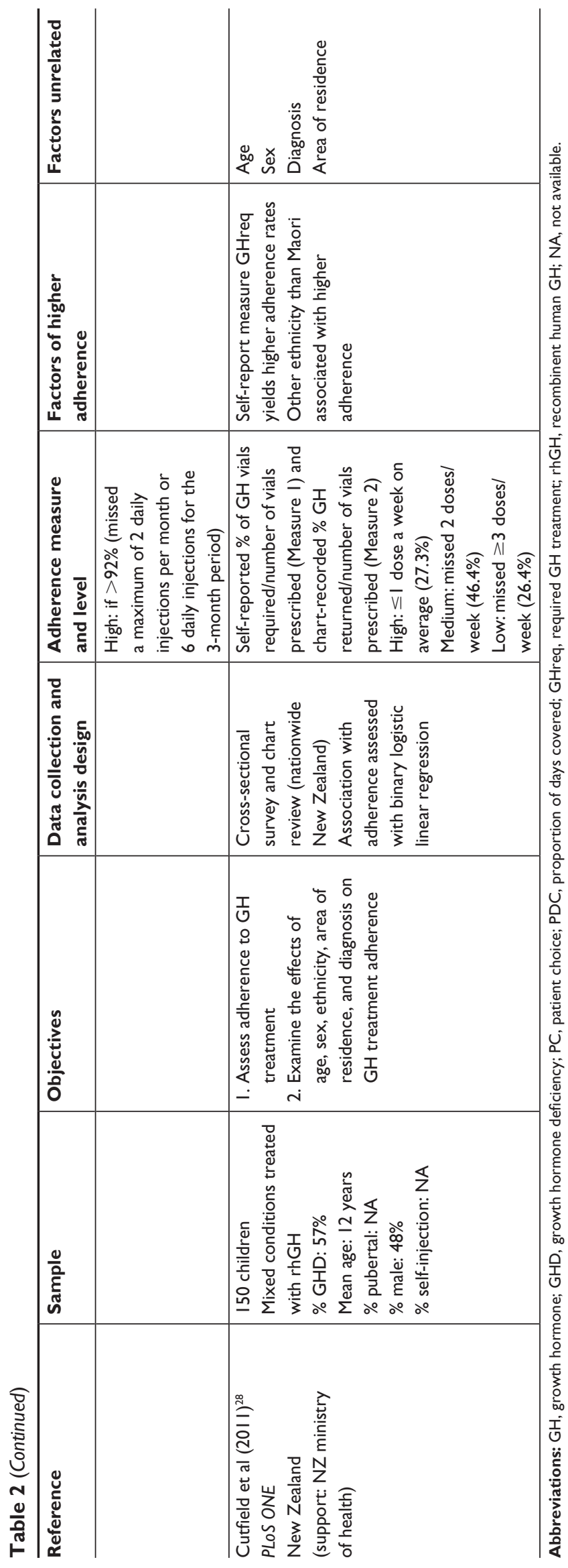

Patients' conditions were mixed with all treatments being rhGH replacement therapy, and most frequent conditions being growth-related conditions. GHD was the most frequent condition in the studied samples (median $\% \mathrm{GHD}=76 \%$ ). Ten studies were performed in children or adolescents with a median age of 11 years and sex ratio of $57 \%$ males. Sample sizes varied greatly with median $\mathrm{N}=158$ but three studies included $800+$ participants and only two had $<100$ participants. Nine reports mentioned identifying the factors of adherence in their primary or secondary objectives. Most of the studies adopted a cross-sectional data collection with an association with historical data (9/11). In four of these cases, only charts were analyzed. Two were cross-sectional fully self-reported survey. ${ }^{18,22}$ Only one was a prospective cohort follow-up..$^{25}$ This implies strong limitations on causal interpretations as, in most cases, factors did not precede the adherence outcome.

Adherence was measured in three different ways. Four studies used the number of missed injection with typically $\geq 1$ missed injection being a threshold for lower adherence, five used prescriptions filled or medication possession ratios, and one study used both, from chart reviews or pharmacist reports. Finally, two studies used data recorded by an electronic device (easypod). ${ }^{26,27}$ In addition, one study also reported on persistence, that is, the time interval between a patient's first and last delivery of GH.

\section{Adherence}

The levels were difficult to synthesize given the variety of measures. Results of calculations on the basis of injection missed indicate a frequency of low adherence, that is, one or more injection missed $/$ week, of median $=25 \%$ in the studied samples. From the calculations on prescriptions filled, authordescribed low levels were observed in a median of $26 \%$ of patients. On the basis of electronic devices recording, the median proportion of those missing more than one dose is $21 \%$. Overall, recent reports indicated that approximately one fourth of participants, children, adolescents, and adults had clear issues with adherence to rhGH treatment. This proportion is consistent across outcome measures.

\section{Factors of adherence}

A wide range of factors have been studied since 2011, from parents' level of education ${ }^{18}$ to being able to choose an injection device. ${ }^{19}$ When classifying these factors in the categories from the diabetes literature (Table 1), we found a striking evidence that a large majority of studies (10/11) investigated non-modifiable sociodemographics and contextual factors 
such as current age, diagnosis, or pubertal status. A majority of studies also explored practical issues such as the impact of device type or product (6/11). In sharp contrast, among the eleven studies, only one surveyed individual predictors (eg, understanding consequences, knowledge of the disease) and social aspects (quality of parent-child relations over treatment). ${ }^{18}$ In addition, only two reports explored relationship issues (eg, satisfaction with the health care team ${ }^{18}$ and type of health care, home vs stores). ${ }^{24}$ Importantly, most studies explored one or two domains of factors of adherence (median number of domains $=2$ ), but modifiable domains were only investigated $50 \%$ of the time. This is probably related to the high frequency of chart-based studies among the reports. This observation shows that there is a great potential in the future for the investigation of modifiable factors within the individual, social, and health care domains, beside practical issues as device type in the GH-treatment literature.

When examining the factors whose relation was found significant with the measures of adherence, we found arguments suggesting that younger children treated by their parents have higher adherence rates than pubertal-adolescents caring for themselves ${ }^{18,21,23,26}$ (but this relation was not significant in all reports). ${ }^{24,25}$ Higher levels of education in parents were also consistently related to higher adherence. ${ }^{18,2}$ In contrast, studies tended to show no relation with sex, diagnosis type, or device/product used ${ }^{19,20,23,25}$ except the fact that storage-flexible products were associated with higher adherence. $^{22}$

Importantly, we collected comments or interpretations in the discussion sections on key factors that according to authors may explain treatment adherence and thus should be studied in the future (Table 3). This analysis revealed that at least six of eleven reports recommended to investigate modifiable explanatory factors. For instance, a strong case was made in favor of perceived barriers and benefits, ${ }^{20,23,28}$ physician-patient relationship, ${ }^{20,23,27}$ risk perception, ${ }^{23,27}$ patient knowledge and skills, ${ }^{20,26}$ controllability issues, ${ }^{22,24,27}$ and emotional distress. ${ }^{23,24}$ Notably, these factors can only be studied in real-world observational data collection strategies. It is very significant that so few studies collected evidence on these factors $(1 / 11)$ but that a majority stress their importance in their discussion (more than 6/11). Perhaps, this should serve as a prompt to adopt other research designs in the future (other than retrospective chart review with minimal cross-sectional survey) as chart reviews cannot address a series of key factors like individual motivation or social factors.

Table 3 Domains of factors of adherence to rhGH studied in II reports (20II-2017)

\begin{tabular}{|c|c|c|c|c|c|c|c|}
\hline Reference & $\begin{array}{l}\text { Descriptive } \\
\text { factors }\end{array}$ & $\begin{array}{l}\text { Individual } \\
\text { factors }\end{array}$ & $\begin{array}{l}\text { Social } \\
\text { factors }\end{array}$ & $\begin{array}{l}\text { Practical } \\
\text { factors }\end{array}$ & $\begin{array}{l}\text { Health } \\
\text { care } \\
\text { factors }\end{array}$ & $\begin{array}{l}\text { No } \\
\text { domains }\end{array}$ & $\begin{array}{l}\text { Factors suggested in } \\
\text { the discussion section } \\
\text { of the articles }\end{array}$ \\
\hline $\begin{array}{l}\text { Bagnasco et al }(2017)^{18} \\
\text { Endocrine Practice }\end{array}$ & $x$ & $x$ & $x$ & $x$ & $x$ & 5 & \\
\hline $\begin{array}{l}\text { Gau and Takasawa } \\
(2017)^{19} \\
\text { Journal of Pediatric } \\
\text { Endocrinology and } \\
\text { Metabolism }\end{array}$ & $x$ & & & $x$ & & 2 & $\begin{array}{l}\text { Socioeconomic factors (eg, } \\
\text { mother's education level) } \\
\text { Type of device } \\
\text { Pubertal stage }\end{array}$ \\
\hline $\begin{array}{l}\text { Auer et al }(2016)^{20} \\
\text { Clinical Endocrinology }\end{array}$ & $x$ & & & $x$ & & 2 & $\begin{array}{l}\text { Forgetfulness } \\
\text { Side effects of treatment } \\
\text { Perceived treatment } \\
\text { benefits } \\
\text { Physician-patient } \\
\text { relationship } \\
\text { Patient education }\end{array}$ \\
\hline $\begin{array}{l}\text { de Pedro et al }(2016)^{21} \\
\text { Growth Hormone \& IGF } \\
\text { Research }\end{array}$ & $x$ & & & & & 1 & \\
\hline $\begin{array}{l}\text { Kappelgaard et al } \\
(2015)^{22} \\
\text { Expert Review of } \\
\text { Medical Devices }\end{array}$ & & & & $x$ & & 1 & $\begin{array}{l}\text { Choice of device } \\
\text { Easy-to-use device }\end{array}$ \\
\hline
\end{tabular}

(Continued) 
Table 3 (Continued)

\begin{tabular}{|c|c|c|c|c|c|c|c|}
\hline Reference & $\begin{array}{l}\text { Descriptive } \\
\text { factors }\end{array}$ & $\begin{array}{l}\text { Individual } \\
\text { factors }\end{array}$ & $\begin{array}{l}\text { Social } \\
\text { factors }\end{array}$ & $\begin{array}{l}\text { Practical } \\
\text { factors }\end{array}$ & $\begin{array}{l}\text { Health } \\
\text { care } \\
\text { factors }\end{array}$ & $\begin{array}{l}\text { No } \\
\text { domains }\end{array}$ & $\begin{array}{l}\text { Factors suggested in } \\
\text { the discussion section } \\
\text { of the articles }\end{array}$ \\
\hline $\begin{array}{l}\text { Lass and Reinehr } \\
(2015)^{23} \\
\text { Hormone Research in } \\
\text { Paediatrics }\end{array}$ & $x$ & & & $x$ & & 2 & $\begin{array}{l}\text { Education level } \\
\text { Psychological and } \\
\text { emotional problems } \\
\text { Social issues } \\
\text { Technical handling issues } \\
\text { Misconceptions about } \\
\text { consequences of missed } \\
\text { doses } \\
\text { Discomfort with injections } \\
\text { Dissatisfaction with results } \\
\text { Inadequate contact with } \\
\text { HCPs }\end{array}$ \\
\hline $\begin{array}{l}\text { Spoudeas et al }(2014)^{24} \\
\text { Patient Preference and } \\
\text { Adherence }\end{array}$ & $x$ & & & & $x$ & 2 & $\begin{array}{l}\text { Lack of choice of delivery } \\
\text { device } \\
\text { Person who administers } \\
\text { the dose } \\
\text { Injection discomfort or } \\
\text { anxiety } \\
\text { Patient support (injection } \\
\text { training and contact with } \\
\text { HCP) } \\
\text { Too much involvement in } \\
\text { treatment decisions }\end{array}$ \\
\hline $\begin{array}{l}\text { Aydın et al }(20 \mid 4)^{25} \\
\text { Endocrine Practice }\end{array}$ & $x$ & & & $x$ & & 2 & $\begin{array}{l}\text { Neglecting to renew the } \\
\text { prescription } \\
\text { Forgetting to administer } \\
\text { the drug } \\
\text { Vacation/break from taking } \\
\text { the medication } \\
\text { Problems with the delivery } \\
\text { device }\end{array}$ \\
\hline $\begin{array}{l}\text { Hartmann et al } \\
(2013)^{26} \\
\text { Hormone Research in } \\
\text { Paediatrics }\end{array}$ & $x$ & & & & & I & $\begin{array}{l}\text { Education } \\
\text { Psychological, emotional, } \\
\text { and social problems } \\
\text { Delivery device } \\
\text { Support for adolescents } \\
\text { and their families }\end{array}$ \\
\hline $\begin{array}{l}\text { Bozzola et al }(20 \mathrm{II})^{27} \\
\text { BMC Endocrine } \\
\text { Disorders }\end{array}$ & $x$ & & & & $x$ & 2 & $\begin{array}{l}\text { Duration of treatment } \\
\text { (participants become less } \\
\text { enthusiastic and motivated) } \\
\text { Misperceptions about the } \\
\text { consequences of missed } \\
\text { GH doses } \\
\text { Discomfort with injections } \\
\text { Dissatisfaction with } \\
\text { treatment results } \\
\text { Inadequate contact with } \\
\text { HCP } \\
\text { Patient not involved in } \\
\text { treatment decisions } \\
\text { Choice of the delivery } \\
\text { device }\end{array}$ \\
\hline
\end{tabular}

(Continued) 
Table 3 (Continued)

\begin{tabular}{|l|l|l|l|l|l|l|l|}
\hline Reference & $\begin{array}{l}\text { Descriptive } \\
\text { factors }\end{array}$ & $\begin{array}{l}\text { Individual } \\
\text { factors }\end{array}$ & $\begin{array}{l}\text { Social } \\
\text { factors }\end{array}$ & $\begin{array}{l}\text { Practical } \\
\text { factors }\end{array}$ & $\begin{array}{l}\text { Health } \\
\text { care } \\
\text { factors }\end{array}$ & $\begin{array}{l}\text { No } \\
\text { domains }\end{array}$ & $\begin{array}{l}\text { Factors suggested in } \\
\text { the discussion section } \\
\text { of the articles }\end{array}$ \\
\hline & & & & & $\begin{array}{l}\text { Use of complicated delivery } \\
\text { devices } \\
\text { Experience with the } \\
\text { delivery device }\end{array}$ \\
\hline $\begin{array}{l}\text { Cutfield et al }(201)^{28} \\
\text { PLoS One }\end{array}$ & $\mathrm{x}$ & & & & & $\begin{array}{l}\text { Injection frequency } \\
\text { Type of device } \\
\text { Lack of perceived benefits } \\
\text { Lack of perceived risks of } \\
\text { noncompliance } \\
\text { Culture and socioeconomic } \\
\text { factors }\end{array}$ \\
\hline
\end{tabular}

Abbreviations: $\mathrm{GH}$, growth hormone; HCP, Health Care Professionals; rhGH, recombinent human GH.

\section{Results: prophylaxis treatment in hemophilia Study selection}

The selection process is presented in a flow diagram (Figure S2). The initial search resulted in 708 hits (PubMed: 137, Embase: 544, CINAHL: 21, PsycINFO: 6). After removing 169 duplicates, 539 items were screened on the basis of their abstract. In case of the absence of abstract, a fulltext was retrieved; 489 were excluded following this pass (eg, adherence was not studied in 316, study design was not empirical in 93). Fifty were thus selected for full-text analysis and 18 of these were excluded for various reasons (eg, seven did not inquire factors and six did not define adherence clearly). Finally, 32 reports were matched to inclusion criteria and relevant to the research question. Sixteen reports were full research articles published in peer-reviewed journals and 16 were conference abstracts. Due to limited details, we could not include abstracts in the full review. The final set of 16 full research articles is summarized in Table 4. ${ }^{29-44}$

\section{Study description}

All the studies were from a single country. Less than $44 \%$ (7/16) were performed in North America. Half of the studies were performed in Europe (8/16), and one was performed in China.

Most of the studies (13/16) included patients treated with prophylaxis regimen as respondents. The others surveyed professionals from treatment centres. ${ }^{41,43,44}$ Hemophilia A was found to be the most frequent condition in the eleven patient samples that gave this detail (median 91\%). The other conditions were Hemophilia B and Von Willebrand disease.
Among the studies with patients, 7 of the 13 studies included children or adolescents. As expected, samples were almost fully composed of boys/men. The median age of adults can be roughly estimated at around 29-39 years and that of children/ adolescents was 12-19 years (some samples were mixed or indicated frequencies of age ranges, Table 4). Patient sample sizes varied greatly with median $\mathrm{N}=78$, where 3 of the 13 studies included $100+$ participants. ${ }^{33,34,42}$ For studies led with professionals, this figure was $\mathrm{N}=71$. Out of 16 studies, 12 reports mentioned identifying the factors or correlates of adherence as their primary or secondary objectives. More than two thirds of studies (11/16) adopted a cross-sectional data collection including those with retrospective data from chart review, ${ }^{29,30,32,33,35,36,39,40,42}$ whereas two were prepost evaluations of interventions. ${ }^{31,41}$ Two had prospective follow-up designs, ${ }^{34,37}$ and one was a qualitative inquiry on the experience of treatment in adults. ${ }^{38}$

In quantitative studies, adherence was measured in three different ways. Ten of the 16 studies appeared to rely on selfreport to evaluate adherence. Seven studies used the VERITAS-Pro to evaluate the level of adherence in respondents. ${ }^{45,46}$ This tool is a 24-item self-report questionnaire. It consists of six subscales that examine the extent to which participants take their injections at the recommended time (timing), use the recommended dose (dosing), plan ahead to ensure they have enough supplies (planning), remember to take their injections (remembering), skip injections (skipping), and communicate with the hemophilia center appropriately (communicating). Items may be summed to yield a global adherence score. ${ }^{29-33}$, ${ }^{35,42}$ One study used other non-illness-specific self-reports (Morisky/Morisky Medication-taking Adherence Scale-4) ${ }^{39}$ 


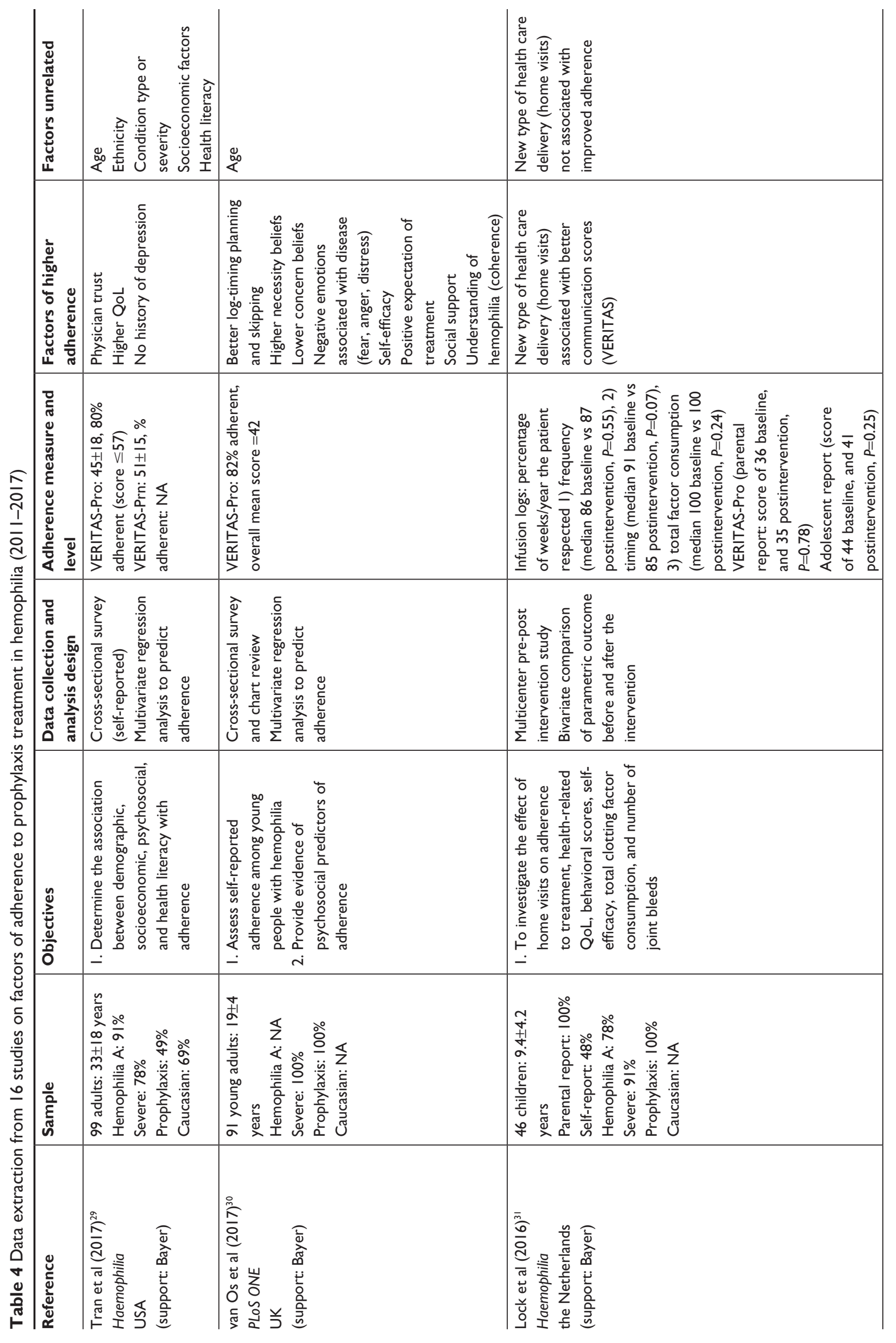




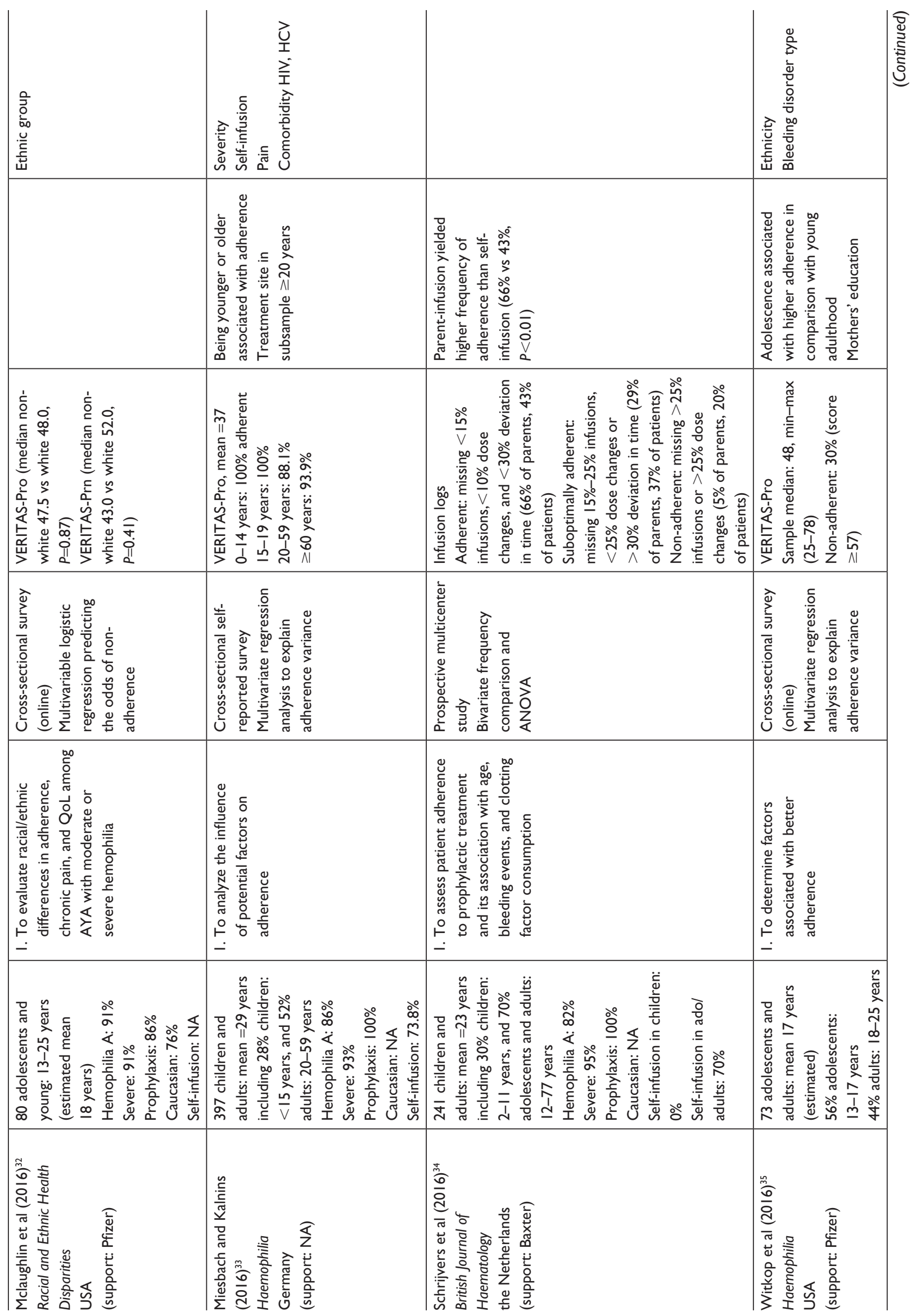




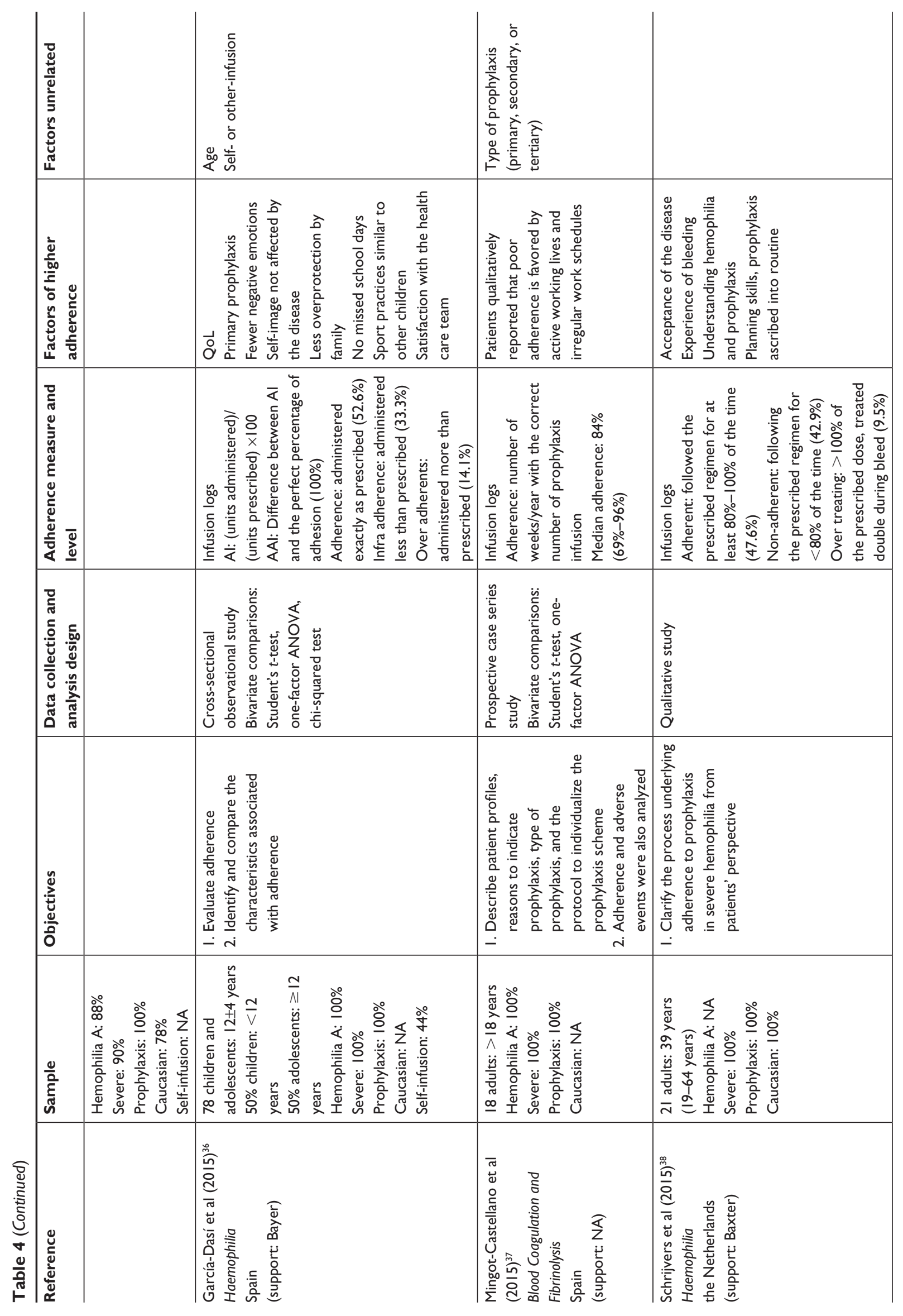




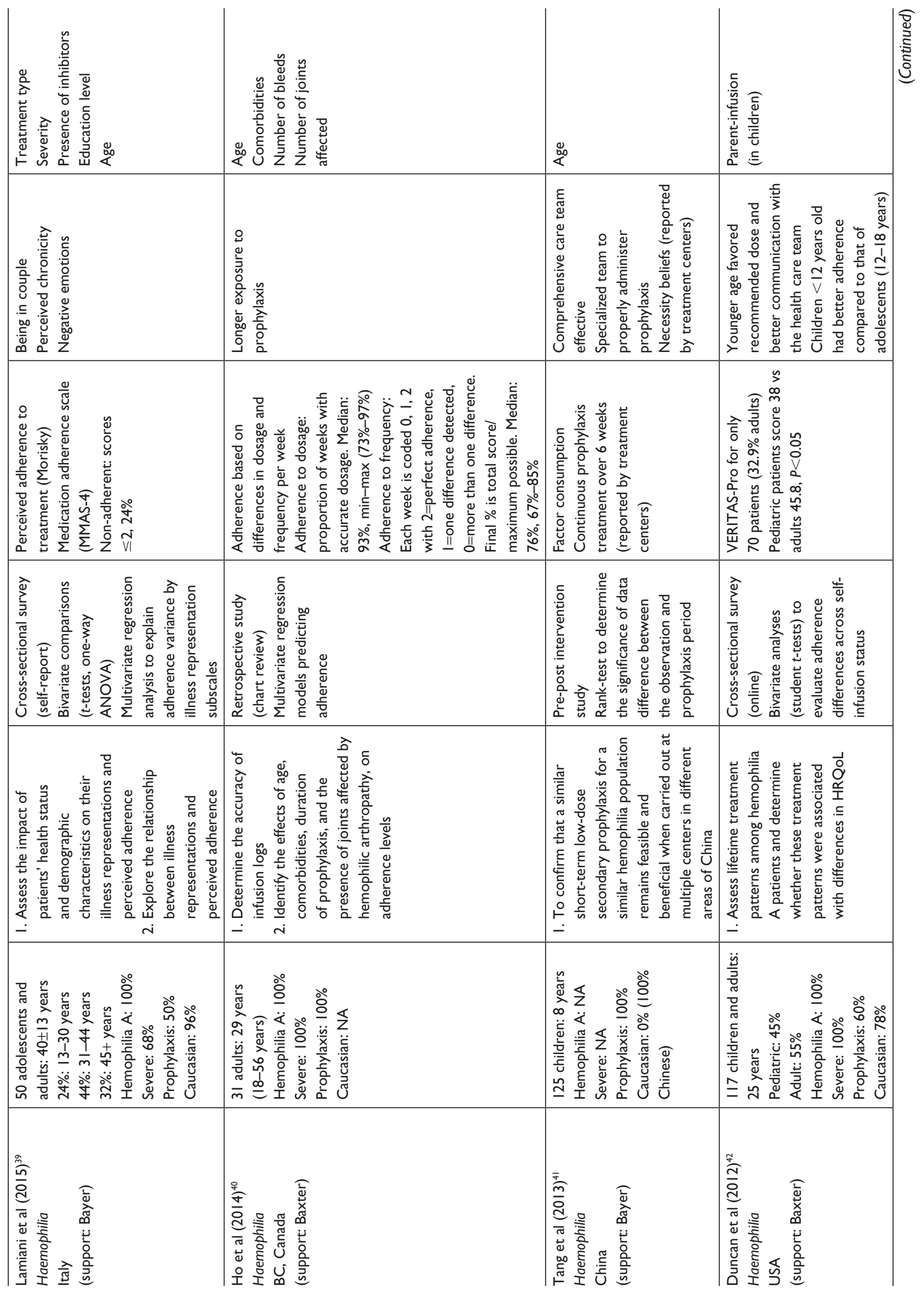




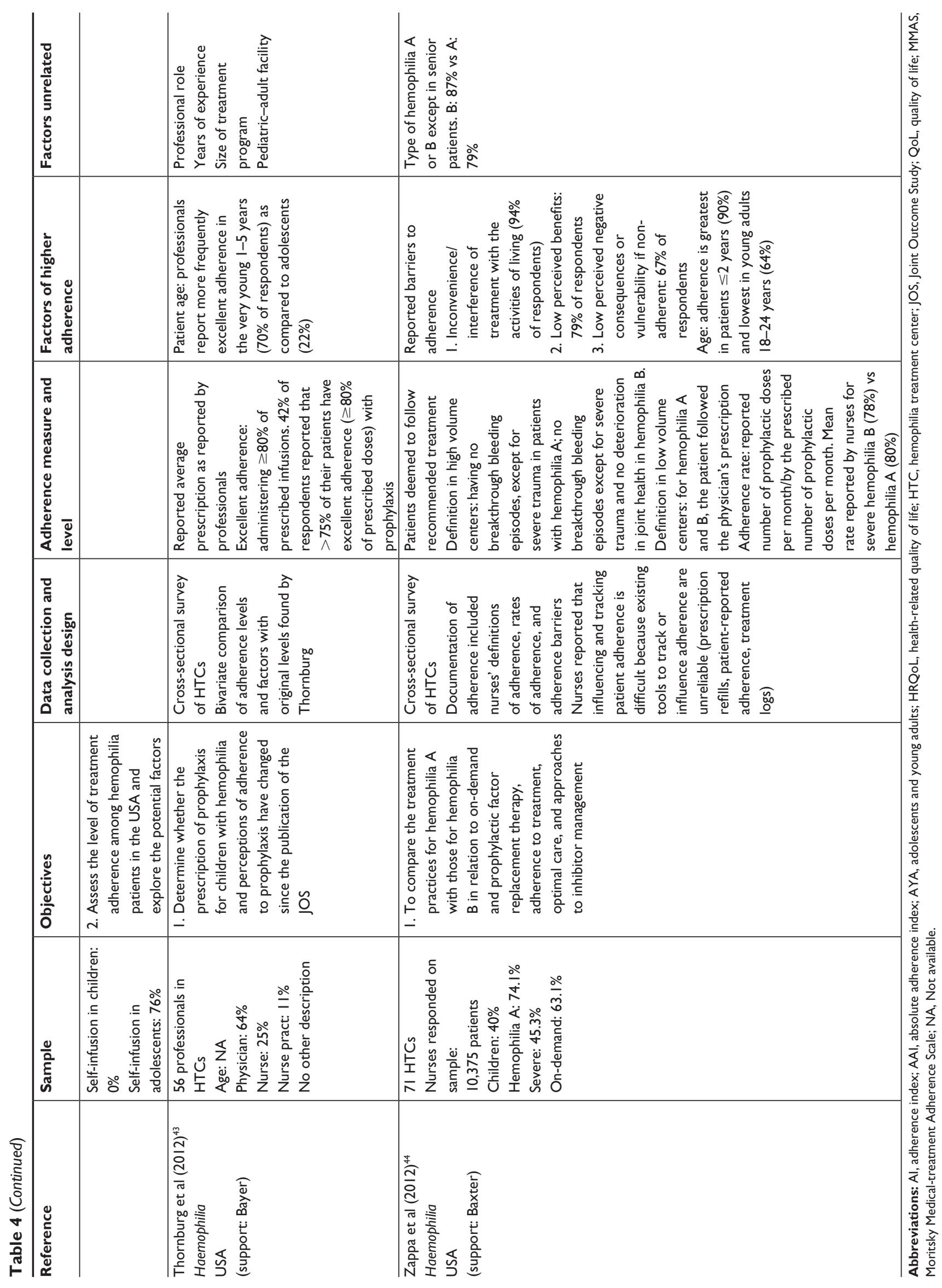


and two reports collected perceived frequencies of adherence in adult patients ${ }^{38}$ and professionals. ${ }^{43}$ Five studies also used infusion logs or diaries. ${ }^{31,34,36-38}$ Finally, five studies used an objective adherence index, computed from a ratio of units administered divided by units prescribed..$^{34,36,40,41,44}$ However, a wide variety of definitions of adherence was observed among these studies: a high adherence could refer to a perfect administration (no errors) ${ }^{36}$ or to limited errors in infusing, dosing, or timing ${ }^{34}$ or to the absence of consequent bleeding episodes. ${ }^{44}$ Suboptimal and non-adherence on infusing frequency was generally defined as $>15 \%-25 \%$ missed infusions. ${ }^{47}$ Although several measures bore a documented validity, including selfreport tools, they probably described different aspects of treatment behavior.

\section{Adherence}

The levels were difficult to synthesize given the variety of measures used. If we rely on definitions given by authors of suboptimal levels in adherence, frequencies varied from $12 \%{ }^{33}$ to $43 \%$. $^{38}$ In those reports indicating frequencies according to existing thresholds, most indicated a low adherence rate of around a median of $20 \%$ for the infusion frequency. However, this rate of non-adherence was far lower in younger children who were infused by their parents (eg, 5\% in Schrijvers). ${ }^{34}$ When examining self-report data only with high measure homogeneity, VERITAS-Pro levels were at a median of 45.5/100 (higher scores = lower adherence) in six self-report studies performed in 857 individuals who self-infused. Overall, reports from years 2011-2017 indicated that approximately one fifth of participants, children, adolescents, and adults, had issues with adherence to factor replacement treatment.

\section{Factors of adherence}

A wide range of factors have been studied since 2011, from new types of health care delivery ${ }^{31}$ to overprotection in the family. ${ }^{36}$

When classifying these factors in the categories from the diabetes literature (Table 1), we found a significant subset of five studies investigating exclusively non-modifiable sociodemographics and contextual factors such as current age, diagnosis, parent-infusion vs self-infusion (Table 5). Reports agreed on the observation that self-infusion at the adolescence and among young adulthood represented a risk for adherence. ${ }^{34,42}$ However, in contrast with the rhGH literature, individual factors have been more frequently studied in relation to hemophilia prophylaxis during the recent period 2011-2017 (seven reports). These reports found that neces- sity beliefs or perceived vulnerability (eg, experience of bleeding) as well as perceived benefits of treatment were fundamental aspects of motivation underlying adherence. ${ }^{30,41,44}$ We also found arguments suggesting that negative emotions or the absence of history of depression would be associated with lower adherence rates. ${ }^{29,30,36,39}$ Finally, understanding hemophilia and feeling capable of planning were also associated with higher adherence. ${ }^{30,38}$

Health care factors were studied through communication issues with the treatment centers and professional caregivers (5/16 studies). Although an intense follow-up did not yield stronger results on adherence, communication quality and trust in health care providers were found to be core factors of adherence. ${ }^{29,31,36}$ Interestingly, a mere two reports found an impact of social factors such as relations with parents (in children) or working schedules (in adults). ${ }^{36,37,44}$

Importantly, most studies explored one or two domains of factors of adherence (median number of domains $=1.5$ ), but modifiable domains were only investigated two thirds of the time. This means that one third of studies still only considers non-modifiable correlates. This is probably related to the high frequency of chart-based studies among the reports.

When examining factors whose relation was found significant with the measures of adherence, we found arguments suggesting that individual and health care factors would explain adherence. Yet reports found negative results on the impact of age when considered in isolation. This is probably because age is confounded with self-other infusion. When age was controlled for, parent-infusion was systematically related with higher levels of adherence. ${ }^{34,42,43}$ A higher level of education in parents was also associated with better adherence. Finally, studies tended to show no relation with diagnosis type, but hemophilia B concerned a very small number of individuals. Overall, this broad picture of the results from Table 4 suggests that transition periods, including the passage to self-care, deserve a particular attention and that social factors including relationships with parents are still under investigated.

We also collected comments or interpretations of study authors in the discussion sections on which key factors may explain treatment adherence and thus should be studied in the future (Table 5). This analysis reveals that a large number of authors recommended to address social factors such as social support, social stigma, communication with parents and the health care team, social norms or the sense that the treatment is normal, as well as transition points in autonomy. ${ }^{29,31,35,36,42}$ This recommendation strongly contrasts with the available literature and points to a gap in knowledge. Cost and financial 
Table 5 Domains of factors of adherence to prophylaxis treatment in hemophilia in 16 reports (2011-2017)

\begin{tabular}{|c|c|c|c|c|c|c|c|}
\hline Reference & $\begin{array}{l}\text { Descriptive } \\
\text { factors }\end{array}$ & $\begin{array}{l}\text { Individual } \\
\text { factors }\end{array}$ & $\begin{array}{l}\text { Social } \\
\text { factors }\end{array}$ & $\begin{array}{l}\text { Practical } \\
\text { factors }\end{array}$ & $\begin{array}{l}\text { Health care } \\
\text { factors }\end{array}$ & $\begin{array}{l}\text { No } \\
\text { domains }\end{array}$ & $\begin{array}{l}\text { Factors suggested in } \\
\text { the discussion }\end{array}$ \\
\hline $\begin{array}{l}\text { Tran et al }(2017)^{29} \\
\text { Haemophilia }\end{array}$ & & $x$ & & & $x$ & 2 & $\begin{array}{l}\text { Family support } \\
\text { Social support } \\
\text { Social stigma } \\
\text { Necessity beliefs } \\
\text { Concern beliefs } \\
\text { Health-system factors: } \\
\text { individual formularies, } \\
\text { prior-authorization } \\
\text { requirements, cost sharing }\end{array}$ \\
\hline $\begin{array}{l}\text { van Os et al } \\
(2017)^{30} \\
\text { PLOS ONE }\end{array}$ & & $x$ & $x$ & & & 2 & Treatment cost \\
\hline $\begin{array}{l}\text { Lock et al }(2016)^{31} \\
\text { Haemophilia }\end{array}$ & & & & & $x$ & 1 & $\begin{array}{l}\text { Communication between } \\
\text { parents and the treatment } \\
\text { center }\end{array}$ \\
\hline $\begin{array}{l}\text { Mclaughlin et al } \\
(2016)^{32} \\
\text { Racial and Ethnic } \\
\text { Health Disparities }\end{array}$ & & & & & & 0 & NA \\
\hline $\begin{array}{l}\text { Miesbach and } \\
\text { Kalnins }(2016)^{33} \\
\text { Haemophilia }\end{array}$ & $x$ & & & & $x$ & 2 & $\begin{array}{l}\text { Infusion timing } \\
\text { Frequency of infusions } \\
\text { Perceived benefits of } \\
\text { treatment }\end{array}$ \\
\hline $\begin{array}{l}\text { Schrijvers et al } \\
(2016)^{34} \\
\text { British Journal of } \\
\text { Haematology }\end{array}$ & $x$ & & & & & 1 & $\begin{array}{l}\text { Accepting the disease } \\
\text { Self-management skills } \\
\text { Infusion timing }\end{array}$ \\
\hline $\begin{array}{l}\text { Witkop et al } \\
(2016)^{35} \\
\text { Haemophilia }\end{array}$ & $x$ & & & & & 1 & $\begin{array}{l}\text { Attitudes toward } \\
\text { prophylaxis treatment } \\
\text { Parental support } \\
\text { Motivation and } \\
\text { encouragement } \\
\text { Sense of normality } \\
\text { (treatment is normal) } \\
\text { Perceived benefits, } \\
\text { experience of results }\end{array}$ \\
\hline $\begin{array}{l}\text { García-Dasí et al } \\
(2015)^{36} \\
\text { Haemophilia }\end{array}$ & $x$ & $x$ & $x$ & $x$ & $x$ & 5 & $\begin{array}{l}\text { Puberty } \\
\text { Emotional aspects } \\
\text { Accepting the disease } \\
\text { Family attitude: } \\
\text { watchfulness vs } \\
\text { overprotection }\end{array}$ \\
\hline $\begin{array}{l}\text { Mingot-Castellano } \\
\text { et al }(2015)^{37} \\
\text { Blood Coagulation } \\
\text { and Fibrinolysis }\end{array}$ & & & & $x$ & & 1 & NA \\
\hline $\begin{array}{l}\text { Schrijvers et al } \\
(2015)^{38} \\
\text { Haemophilia }\end{array}$ & $x$ & $x$ & & $x$ & & 3 & $\begin{array}{l}\text { Perception of self- } \\
\text { monitoring } \\
\text { Self-management skills } \\
\text { Age (position of hemophilia } \\
\text { in adolescent patients) }\end{array}$ \\
\hline $\begin{array}{l}\text { Lamiani et al } \\
(2015)^{39} \\
\text { Haemophilia }\end{array}$ & $x$ & $x$ & & & & 2 & NA \\
\hline
\end{tabular}

(Continued) 
Table 5 (Continued)

\begin{tabular}{|c|c|c|c|c|c|c|c|}
\hline Reference & $\begin{array}{l}\text { Descriptive } \\
\text { factors }\end{array}$ & $\begin{array}{l}\text { Individual } \\
\text { factors }\end{array}$ & $\begin{array}{l}\text { Social } \\
\text { factors }\end{array}$ & $\begin{array}{l}\text { Practical } \\
\text { factors }\end{array}$ & $\begin{array}{l}\text { Health care } \\
\text { factors }\end{array}$ & $\begin{array}{l}\text { No } \\
\text { domains }\end{array}$ & $\begin{array}{l}\text { Factors suggested in } \\
\text { the discussion }\end{array}$ \\
\hline $\begin{array}{l}\text { Ho et al }(2014)^{40} \\
\text { Haemophilia }\end{array}$ & $x$ & & & & & 1 & $\begin{array}{l}\text { Intensity of treatment } \\
\text { regimen } \\
\text { Cost of treatment }\end{array}$ \\
\hline $\begin{array}{l}\text { Tang et al }(2013)^{4 I} \\
\text { Haemophilia }\end{array}$ & & $x$ & & & $x$ & 2 & $\begin{array}{l}\text { Economic constraint } \\
\text { Limitation in factor } \\
\text { concentrate availability } \\
\text { Education (potential } \\
\text { benefits on the child's well- } \\
\text { being and quality of life) }\end{array}$ \\
\hline $\begin{array}{l}\text { Duncan et al } \\
(2012)^{42} \\
\text { Haemophilia }\end{array}$ & $x$ & & & & & 1 & $\begin{array}{l}\text { Transition points: shift } \\
\text { from infused by family or } \\
\text { nurse to self-infusion and } \\
\text { switch from a prophylaxis } \\
\text { regimen to on-demand } \\
\text { treatment }\end{array}$ \\
\hline $\begin{array}{l}\text { Thornburg et al } \\
(20 \mid 2)^{43} \\
\text { Haemophilia }\end{array}$ & $x$ & & & & & 1 & $\begin{array}{l}\text { Financial concerns } \\
\text { Accessibility of treatment } \\
\text { Self-infusion vs other- } \\
\text { infusion } \\
\text { Education } \\
\text { Frequency of infusion }\end{array}$ \\
\hline $\begin{array}{l}\text { Zappa et al }(2012)^{44} \\
\text { Haemophilia }\end{array}$ & $x$ & $x$ & & $x$ & & 3 & NA \\
\hline
\end{tabular}

Abbreviation: NA, not available.

issues were also recommended as an important target in countries where full coverage is not warranted..$^{29,30,40,43}$ Finally, as transition points were recognized as vulnerability periods, self-management skills and self-infusion were recommended to be studied thoroughly. It is noticeable that no intervention during the study period sought to influence adherence through improving self-management during the transition period. This is reflected by the very limited number of prepost intervention studies or prospective studies performed over recent years. ${ }^{31,37,41}$

\section{Discussion}

The present research is an original attempt to review and compare factors of adherence of two resembling treatment regimen, rhGH and blood factor replacement therapy. From the examination of 27 reports dated 2011-2017, we estimated that approximately one in four to one in five participants $(20 \%-25 \%)$ had issues with adherence. When exploring factors, we found a consistent pattern suggesting that adolescent or older children caring for themselves had lower adherence levels than children whose treatment was managed by parents. Importantly, about one third to half of the body of research did not investigate modifiable factors. Individual and relational predictors were clearly understudied, an observation that pointed to a great potential of development for future research in this field, especially in rhGH-treated conditions. This contrasted with study authors' statements in discussion sections of their articles to study individual and relational factors in future research, in both of the studied clinical domains.

The systematic review of adherence factors yielded the observation that some factor domains have scarcely been studied and would deserve sustained attention by future researchers. It is particularly the case of individual factors in rhGH therapy and social factors in hemophilia prophylaxis treatment. This contrasts with the body of research on the effect of device and choice of device, which is not surprising as most of this research is supported by the industry. Unsurprisingly in rhGH therapy, the research showed that choice of device or device reducing pain and discomfort yielded improved adherence and that electronic devices giving feedbacks and prompts may help improve adherence. It is important to note that the lack of information on certain domains is probably not attributable to the fact that such factors do not influence treatment behaviors in GH-treated conditions and hemophilia, but most probably because of a lack of research. As evidenced in the high frequencies of studies focusing on non-modifiable factors, the research in 
this field has mainly been descriptive and focused on simple easy-to-measure factors, such as age, sex, or type of device. However, the picture emerging from the recent literature reviewed here suggests that modifiable factors of adherence have somewhat been more investigated in hemophilia prophylaxis than in rhGH treatment. Although the research on non-modifiable factors may be informative, it cannot lead to appropriate intervention. Consequently, future research endeavors should complement the evidence, particularly in the domains of modifiable factors, such as coping styles, health beliefs and perceptions (individual and family), parental involvement, peer support, or social stigma. Although the choice among these target factors can be guided by theory, ${ }^{48}$ it would be appropriate to confirm them with patients or families, probably in a set of qualitative inquiries identifying the views of participants themselves on barriers and facilitators of adherence. Notably, such inquiries have been performed in hemophilia ${ }^{49}$ but, to our knowledge, they are not available in GH-treated conditions.

Based on the evidence reviewed, one could bridge the identified domains with theoretical models that are commonly employed to predict and change health behaviors in risk prevention research to favor a better articulation with intervention development. Although no systematic analysis has been done to date, a first look at the factors identified here and in previous reviews ${ }^{6,11}$ suggest that a few core factors from the two right columns of Tables 2 and 4 are strongly anchored in social-cognitive theories of change: ${ }^{50}$ 1) individual's self-efficacy or confidence in one's ability to complete treatment behaviors; 2) outcome expectancies or the positive or negative consequences of each behavior one anticipates (eg, necessity/concern balance); 3) illnessrelated family conflict and the position of illness in childparent relationships, 4) communication in the family, 5) parental involvement and monitoring, 6) parental support; 7) the interplay of factors at multiple levels, including the children, their family, community, and the health care system. ${ }^{50}$ A large body of treatment behavior research actually uses the framework of the Theory of Planned Behavior ${ }^{48}$ to design surveys and interventions to predict health behaviors. This includes social norms and practical barriers, which are relevant domains of factors in adherence research. Finally, although psychological issues have seldom been studied in rhGH and hemophilia treatments (with the exception in $\mathrm{rhGH}^{18}$ and in hemophilia ${ }^{29,30,36,38,39,41,44}$ ), it is probable that distress, depression, anxiety, and other internalized or externalized issues hamper adherence, ${ }^{51}$ as it is the case with diabetes self-management. ${ }^{52}$
The methodological rigor of the literature on factors of adherence should also be discussed. In both treatment types, we found important limitations to causal hypotheses linking factors and adherence measures as a large majority of studies were cross-sectional. ${ }^{53}$ As we are interested in modifiable factors, it is necessary that the measurement of factors precedes the measurement of adherence. ${ }^{53}$ This points to the necessity of more frequent longitudinal follow-ups to collect real-world data or intervention designs where factors are manipulated. We found no reports in the study period attempting at systematically modifying knowledge, understanding, perceived necessity or concern, and their effect on adherence. Consequently, there is huge potential for interventional pre-post research in this field, including those increasing patients' perceived benefits of adherence and perceived vulnerability to adverse consequences of non-adherence. Coherent with a recent systematic review, such intervention should be agespecific, include the family, and enhance access to care. ${ }^{54}$

Importantly, the adherence research reviewed here consistently points to a vulnerable period during early teenage until young adulthood. Previous reports in rhGH and blood factor replacement therapy have demonstrated that adolescence is a vulnerable period especially as young people will transition to self-care. ${ }^{55,56}$ This is postulated to result from the extra burden that managing injections imposes on the already challenging nature of adolescence. ${ }^{7,57}$ For many adolescents, injecting may be viewed as a nonessential or meaningless task. The need to manage injections may significantly affect their ability to completely partake in day-to-day activities, which are commonplace for their peer group. Another difficulty for them is also the tendency to focus on the here and now, sometimes because they lack the proper planning competencies, and which makes it hard for them to comprehend the long-term benefits of adhering to the injection regimen. ${ }^{54}$ It is thus necessary to address this specific period when exploring the factors of adherence. ${ }^{7,58}$ In fact, self-management promotion may be most effective if strategically delivered at times of maximal impact. For example, patients' and families' readiness for self-management intervention is probably optimal during the developmental transition of early adolescence when the routine parent-injected treatment is due to change to selfinjection. Consequently, measurement of factors of adherence and intervention initiatives should target this time period.

Two ranges of factors have traditionally appeared as strong predictors of adherence and self-management behaviors in the youth. In younger children, as injections are made by a third party, most often a parent, effectiveness of treatment behaviors lies into how treatment is integrated in 
the daily routine and the position of treatment and illness in the child-parent relationship. For instance, treatment as any other elements may be used by the child to relate with, control or resist to the parent who performs the injection. As the illness is silent in the short-term, with few symptoms, being ill remains abstract for many children, whereas the treatment is very concrete. This is all the more significant as many parents feel guilty to inject because the treatment imposes constraints on the child or makes them feel uncomfortable or painful. Therefore, a large part of adherence issues in younger children may be subsumed to the parent-child relations. ${ }^{50,51,59}$ In older school-age children and teenagers, peer influence may have a major impact on adherence. Recent work has found that young patients often mistakenly believed that friends would have negative reactions to their condition, even though empirical work suggested that friends tend to provide encouragement. Consistently, a link between anxiety in social situations and poor adherence was found, particularly in boys. "Fitting in" appears to drive a part of the issues with adherence in teens. ${ }^{60}$ Similarly, public embarrassment and stress issues were cited by both adult patients and providers to explain missed injection in diabetes. ${ }^{61}$ As the sense of normalcy becomes more acute during adolescence, social norms become a core explanatory factor of adherence in this age range. Consequently, there are both empirical and theoretical arguments to develop a strong endeavor to study individual and relational factors of adherence in GH-treated conditions and hemophilia treated with prophylaxis.

We should acknowledge the limitations of the present work. First, the review is limited to a recent period of 8 years (2011-2017). Although a longer time lapse would have been appropriate, the results would probably have overlapped with pre-existing reviews. ${ }^{6,11}$ As a result, conclusions should only be considered as reflective of the recent period. Second, although the taxonomy emerging from diabetes research in Table 1 is based on reviews and guidelines of the diabetes literature, we cannot rule out that another classification would be equally pertinent. Yet, this taxonomy has good face validity and helped identify gaps in the literature from the point of view of a more frequent illness where adherence research is far more advanced. Third, although we initially wished to include the gray literature and conference abstracts, this revealed inappropriate given the insufficient information to document the retrieved information categories. This led us to discard conference abstracts post hoc. Finally, in order to include as many studies as possible in this very rarely studied field, we did not use any formal instrument to assess the methodology of individual studies. It must also be noted that the two treatments address different situations across conditions with long-term issues ranging from poor joint function (hemophilia) to low stature (GHD). These may trigger a variety of perceptions, concerns, and anticipatory beliefs. Consequently, comparisons across conditions based on the present review should be limited to the broad categories of factors studied in this review.

\section{Conclusion}

In a systematic review of empirical reports documenting factors of adherence in $\mathrm{GH}$-treated conditions $(\mathrm{N}=11)$ and prophylaxis-treated hemophilia $(\mathrm{N}=16)$ from 2011 to 2017, we found a level of suboptimal adherence in $20 \%-25 \%$, comparable to previous reports. We found consistent arguments across conditions suggesting the transition to self-care may be a vulnerability period during the late childhood/early adolescents. When classifying studied factors according to categories emerging from diabetes research, we found the domains of individual factors (eg, perceptions, knowledge, motivation), relational factors (eg, parenting, social norms, stigma), and health care (eg, trust with professional, relationship quality with care team) to be understudied, in comparison with that of demographic context (eg, age, sex, pubertal status) and practical issues (eg, delivery device). Future research should focus on how modifiable factors may explain adherence variability and study how these factors may be targeted by psychosocial and behavioral interventions. ${ }^{51}$

\section{Acknowledgments}

The authors are grateful to Anthony Helou and Josie Visentini for their scientific support and comments on an earlier version of this article.

\section{Disclosure}

Nicolas Garnier is an employee of Pfizer Canada Inc. Serge Sultan, $\mathrm{PhD}$, received financial support from Pfizer to perform a literature survey, analyses, and data presentation in connection with the development of this article. The authors report no other conflicts of interest in this work.

\section{References}

1. Hartmann K, Ittner J, Müller-Rossberg E, et al. Growth hormone treatment adherence in prepubertal and pubertal children with different growth disorders. Horm Res Paediatr. 2013;80(1):1-5.

2. Bozzola M, Pagani S, Iughetti L, Maffeis C, Bozzola E, Meazza C. Adherence to growth hormone therapy: a practical approach. Horm Res Paediatr. 2014;81(5):331-335. 
3. Desrosiers P, O'Brien F, Blethen S. Patient outcomes in the GH Monitor: the effect of delivery device on compliance and growth. Pediatr Endocrinol Rev. 2005;2(Suppl 3):327-331.

4. Fischer K, Steen Carlsson K, Petrini P, et al. Intermediate-dose versus high-dose prophylaxis for severe hemophilia: comparing outcome and costs since the 1970s. Blood. 2013;122(7):1129-1136.

5. Mizrahi T, St-Louis J, Young NL, et al. Adherence to treatment regimen and bleeding rates in a prospective cohort of youth and young adults on low-dose daily prophylaxis for severe hemophilia A. BMC Hematol. 2016;16(1):26.

6. Fisher BG, Acerini CL. Understanding the growth hormone therapy adherence paradigm: a systematic review. Horm Res Paediatr. 2013;79(4): 189-196.

7. Haverkamp F, Gasteyger C. A review of biopsychosocial strategies to prevent and overcome early-recognized poor adherence in growth hormone therapy of children. J Med Econ. 2011;14(4):448-457.

8. Kapoor RR, Burke SA, Sparrow SE, et al. Monitoring of concordance in growth hormone therapy. Arch Dis Child. 2008;93(2):147-148.

9. Schrijvers LH, Kars MC, Beijlevelt-van der Zande M, Peters M, Schuurmans MJ, Fischer K. Unravelling adherence to prophylaxis in haemophilia: a patients' perspective. Haemophilia. 2015;21(5): $612-621$.

10. Schrijvers LH, Cnossen MH, Beijlevelt-van der Zande M, Peters M, Schuurmans MJ, Fischer K. Defining adherence to prophylaxis in haemophilia. Haemophilia. 2016;22(4):e311-e314.

11. Schrijvers LH, Uitslager N, Schuurmans MJ, Fischer K. Barriers and motivators of adherence to prophylactic treatment in haemophilia: a systematic review. Haemophilia. 2013;19(3):355-361.

12. Davies MJ, Gagliardino JJ, Gray LJ, Khunti K, Mohan V, Hughes R. Real-world factors affecting adherence to insulin therapy in patients with Type 1 or Type 2 diabetes mellitus: a systematic review. Diabet Med. 2013;30(5):512-524.

13. Polonsky WH, Henry RR. Poor medication adherence in type 2 diabetes: recognizing the scope of the problem and its key contributors. Patient Prefer Adherence. 2016;10:1299-1307.

14. Peyrot M, Barnett AH, Meneghini LF, Schumm-Draeger P-M. Factors associated with injection omission/non-adherence in the Global Attitudes of Patients and Physicians in Insulin Therapy study. Diabetes Obes Metab. 2012;14(12):1081-1087.

15. Gherman A, Schnur J, Montgomery G, Sassu R, Veresiu I, David D. How are adherent people more likely to think? A meta-analysis of health beliefs and diabetes self-care. Diabetes Educ. 2011;37(3):392-408

16. von Elm E, Altman DG, Egger M, et al. The Strengthening the Reporting of Observational Studies in Epidemiology (STROBE) statement: guidelines for reporting observational studies. PLoS Med. 2007;4(10):e296.

17. Boutron I, Moher D, Altman DG, Schulz KF, Ravaud P; CONSORT Group. Extending the CONSORT statement to randomized trials of nonpharmacologic treatment: explanation and elaboration. Ann Intern Med. 2008;148(4):295-309.

18. Bagnasco F, di Iorgi N, Roveda A, et al. Prevalence and correlates of adherence in children and adolescents treated with growth hormone: A multicenter Italian study. Endocr Pract. 2017;23(8):929-941.

19. Gau M, Takasawa K. Initial patient choice of a growth hormone device improves child and adolescent adherence to and therapeutic effects of growth hormone replacement therapy. J Pediatr Endocrinol Metab. 2017;30(9):989-993.

20. Auer MK, Stieg MR, Hoffmann J, Stalla GK. Is insulin-like growth factor-I a good marker for treatment adherence in growth hormone deficiency in adulthood? Clin Endocrinol. 2016;84(6):862-869.

21. de Pedro S, Murillo M, Salinas I, et al. Variability in adherence to rhGH treatment: Socioeconomic causes and effect on children's growth. Growth Horm IGF Res. 2016;26:32-35.

22. Kappelgaard AM, Metzinger CP, Schnabel D. A web-based survey assessing the impact of storage flexibility on the daily life of patients and caregivers administering growth hormone. Expert Rev Med Devices. 2015;12(5):517-527.
23. Lass $\mathrm{N}$, Reinehr $\mathrm{T}$. Low treatment adherence in pubertal children treated with thyroxin or growth hormone. Horm Res Paediatr. 2015;84(4): $240-247$.

24. Spoudeas HA, Bajaj P, Sommerford N. Maintaining persistence and adherence with subcutaneous growth-hormone therapy in children: comparing jet-delivery and needle-based devices. Patient Prefer Adherence. 2014;8:1255-1263.

25. Aydin BK, Aycan Z, Siklar Z, et al. Adherence to growth hormone therapy: results of a multicenter study. Endocr Pract. 2014;20(1):46-51.

26. Hartmann K, Ittner J, Müller-Rossberg E, et al. Growth hormone treatment adherence in prepubertal and pubertal children with different growth disorders. Horm Res Paediatr. 2013;80(1):1-5.

27. Bozzola M, Colle M, Halldin-Stenlid M, Larroque S, Zignani M, easypod $^{\mathrm{TM}}$ survey study group. Treatment adherence with the easypod ${ }^{\mathrm{TM}}$ growth hormone electronic auto-injector and patient acceptance: survey results from 824 children and their parents. BMC Endocr Disord. 2011;11(1):4.

28. Cutfield WS, Derraik JG, Gunn AJ, et al. Non-compliance with growth hormone treatment in children is common and impairs linear growth. PLoS ONE. 2011;6(1):e16223.

29. Tran DQ, Barry V, Antun A, Ribeiro M, Stein S, Kempton CL. Physician trust and depression influence adherence to factor replacement: a singlecentre cross-sectional study. Haemophilia. 2017;23(1):98-104.

30. van Os SB, Troop NA, Sullivan KR, Hart DP. Adherence to Prophylaxis in Adolescents and Young Adults with Severe Haemophilia: A Quantitative Study with Patients. PLoS ONE. 2017;12(1): e0169880

31. Lock J, Raat H, Peters M, et al. Optimization of home treatment in haemophilia: effects of transmural support by a haemophilia nurse on adherence and quality of life. Haemophilia. 2016;22(6):841-851.

32. Mclaughlin JM, Lambing A, Witkop ML, Anderson TL, Munn J, Tortella B. Racial Differences in Chronic Pain and Quality of Life among Adolescents and Young Adults with Moderate or Severe Hemophilia. J Racial Ethn Health Disparities. 2016;3(1):11-20.

33. Miesbach W, Kalnins W. Adherence to prophylactic treatment in patients with haemophilia in Germany. Haemophilia. 2016;22(5):e367-e374.

34. Schrijvers LH, Beijlevelt-van der Zande M, Peters M, et al. Adherence to prophylaxis and bleeding outcome in haemophilia: a multicentre study. Br J Haematol. 2016;174(3):454-460.

35. Witkop ML, Mclaughlin JM, Anderson TL, Munn JE, Lambing A, Tortella B. Predictors of non-adherence to prescribed prophylactic clotting-factor treatment regimens among adolescent and young adults with a bleeding disorder. Haemophilia. 2016;22(4):e245-e250.

36. García-Dasí M, Aznar JA, Jiménez-Yuste V, et al. Adherence to prophylaxis and quality of life in children and adolescents with severe haemophilia A. Haemophilia. 2015;21(4):458-464.

37. Mingot-Castellano ME, González-Díaz L, Tamayo-Bermejo R, Heiniger-Mazo AI. Adult severe haemophilia A patients under longterm prophylaxis with factor VIII in routine clinical practice. Blood Coagul Fibrinolysis. 2015;26(5):509-514.

38. Schrijvers LH, Kars MC, Beijlevelt-van der Zande M, Peters M, Schuurmans MJ, Fischer K. Unravelling adherence to prophylaxis in haemophilia: a patients' perspective. Haemophilia. 2015;21(5):612-621.

39. Lamiani G, Strada I, Mancuso ME, et al. Factors influencing illness representations and perceived adherence in haemophilic patients: a pilot study. Haemophilia. 2015;21(5):598-604.

40. Ho S, Gue D, Mcintosh K, Bucevska M, Yang M, Jackson S. An objective method for assessing adherence to prophylaxis in adults with severe haemophilia. Haemophilia. 2014;20(1):39-43.

41. Tang L, Wu R, Sun J, et al. Short-term low-dose secondary prophylaxis for severe/moderate haemophilia A children is beneficial to reduce bleed and improve daily activity, but there are obstacle in its execution: a multi-centre pilot study in China. Haemophilia. 2013;19(1): 27-34.

42. Duncan N, Shapiro A, Ye X, Epstein J, Luo MP. Treatment patterns, healthrelated quality of life and adherence to prophylaxis among haemophilia A patients in the United States. Haemophilia. 2012;18(5):760-765. 
43. Thornburg CD, Carpenter S, Zappa S, Munn J, Leissinger C. Current prescription of prophylactic factor infusions and perceived adherence for children and adolescents with haemophilia: a survey of haemophilia healthcare professionals in the United States. Haemophilia. 2012; 18(4):568-574.

44. Zappa S, Mcdaniel M, Marandola J, Allen G. Treatment trends for haemophilia A and haemophilia B in the United States: results from the 2010 practice patterns survey. Haemophilia. 2012;18(3):e140-e153.

45. Duncan NA, Kronenberger WG, Krishnan S, Shapiro AD. Adherence To Prophylactic Treatment In Hemophilia As Measured Using The Veritas-Pro And Annual Bleed Rate (Abr). Value Health. 2014; 17(3):A230.

46. Duncan N, Shapiro A, Ye X, Epstein J, Luo MP. Treatment patterns, health-related quality of life and adherence to prophylaxis among haemophilia A patients in the United States. Haemophilia. 2012;18(5): 760-765.

47. Schrijvers LH, Cnossen MH, Beijlevelt-van der Zande M, Peters M, Schuurmans MJ, Fischer K. Defining adherence to prophylaxis in haemophilia. Haemophilia. 2016;22(4):e311-e314.

48. Ajzen I. Theory of Planned Behaviour Questionnaire. Measurement Instrument Database for the Social Science; 2013. Available from: http://www.midss.org/content/theory-planned-behaviour-questionnaire. Accessed October 1, 2018

49. Schrijvers LH, Kars MC, Beijlevelt-van der Zande M, Peters M, Schuurmans MJ, Fischer K. Unravelling adherence to prophylaxis in haemophilia: a patients' perspective. Haemophilia. 2015;21(5):612-621.

50. Hilliard ME, Powell PW, Anderson BJ. Evidence-based behaviora interventions to promote diabetes management in children, adolescents, and families. Am Psychol. 2016;71(7):590-601.

51. Modi AC, Pai AL, Hommel KA, et al. Pediatric self-management: a framework for research, practice, and policy. Pediatrics. 2012;129(2): e473-e485.
52. Young-Hyman D, de Groot M, Hill-Briggs F, Gonzalez JS, Hood K, Peyrot M. Psychosocial care for people with diabetes: a position statement of the American Diabetes Association. Diabetes Care. 2016; 39(12):2126-2140.

53. Kraemer HC, Kazdin AE, Offord DR, Kessler RC, Jensen PS, Kupfer DJ. Coming to terms with the terms of risk. Arch Gen Psychiatry. 1997; 54(4):337-343.

54. Salema NE, Elliott RA, Glazebrook C. A systematic review of adherence-enhancing interventions in adolescents taking long-term medicines. J Adolesc Health. 2011;49(5):455-466.

55. Geraghty S, Dunkley T, Harrington C, Lindvall K, Maahs J, Sek J. Practice patterns in haemophilia A therapy - global progress towards optimal care. Haemophilia. 2006;12(1):75-81.

56. Rosenfeld RG, Bakker B. Compliance and persistence in pediatric and adult patients receiving growth hormone therapy. Endocr Pract 2008;14(2):143-154.

57. Brand B, Dunn S, Kulkarni R. Challenges in the management of haemophilia on transition from adolescence to adulthood. Eur J Haematol. 2015;95(Suppl 81):30-35.

58. American Diabetes Association. 12. Children and Adolescents. Diabetes Care. 2017;40(Suppl 1):S105-S113.

59. Bérubé S, Mouillard F, Amesse C, Sultan S. Motivational techniques to improve self-care in hemophilia: the need to support autonomy in children. BMC Pediatr. 2016;16(1):1-7.

60. Borus JS, Laffel L. Adherence challenges in the management of type 1 diabetes in adolescents: prevention and intervention. Curr Opin Pediatr. 2010;22(4):405-411.

61. Peyrot M, Barnett AH, Meneghini LF, Schumm-Draeger PM. Insulin adherence behaviours and barriers in the multinational Global Attitudes of Patients and Physicians in Insulin Therapy study. Diabet Med. 2012;29(5):682-689. 


\section{Supplementary materials}

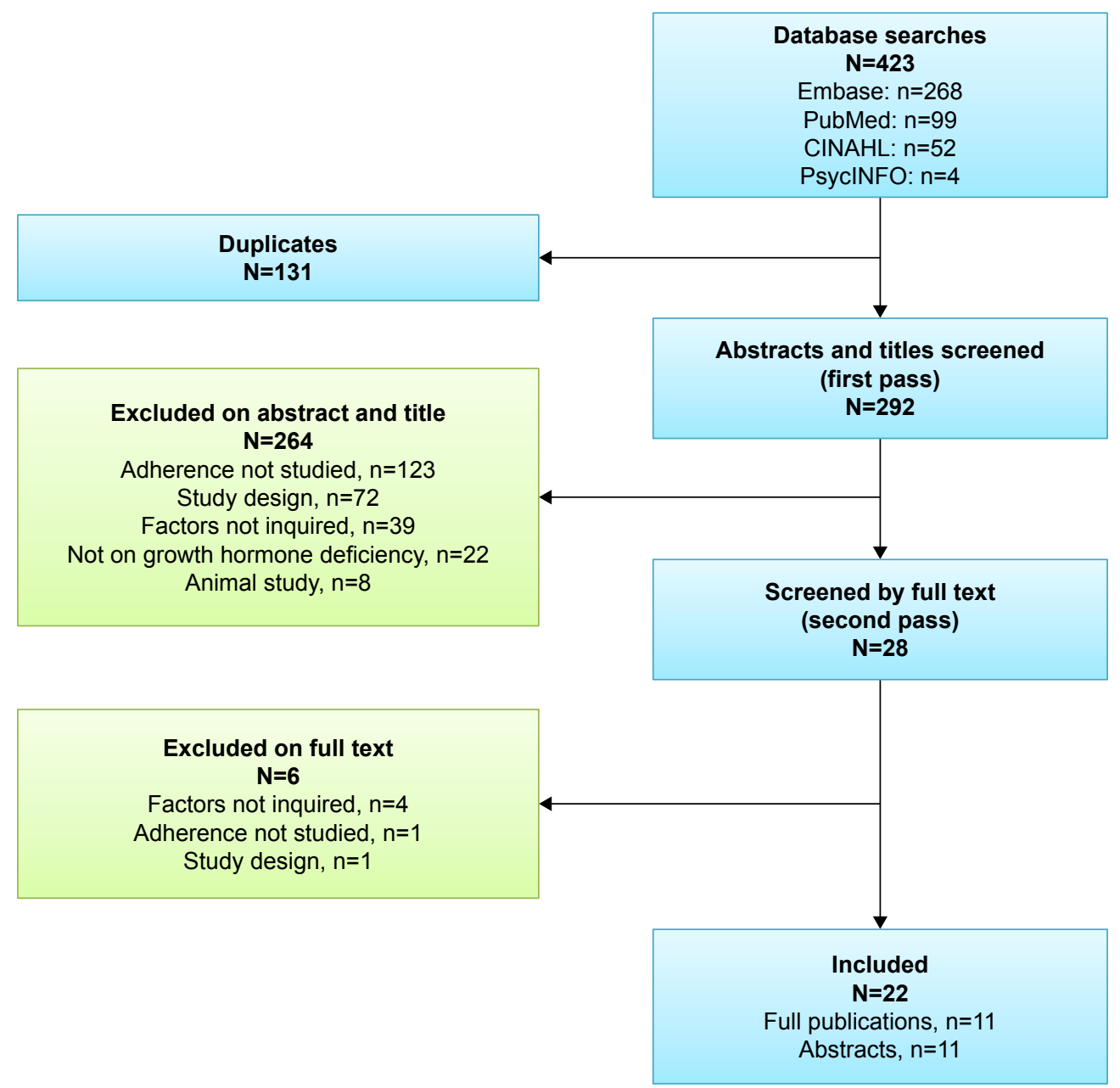

Figure SI Flow diagram of retrieved studies in the review of factors of adherence in patients treated with recombinent human Growth Hormone (rhGH), $20 \mathrm{II-20I7.}$ 


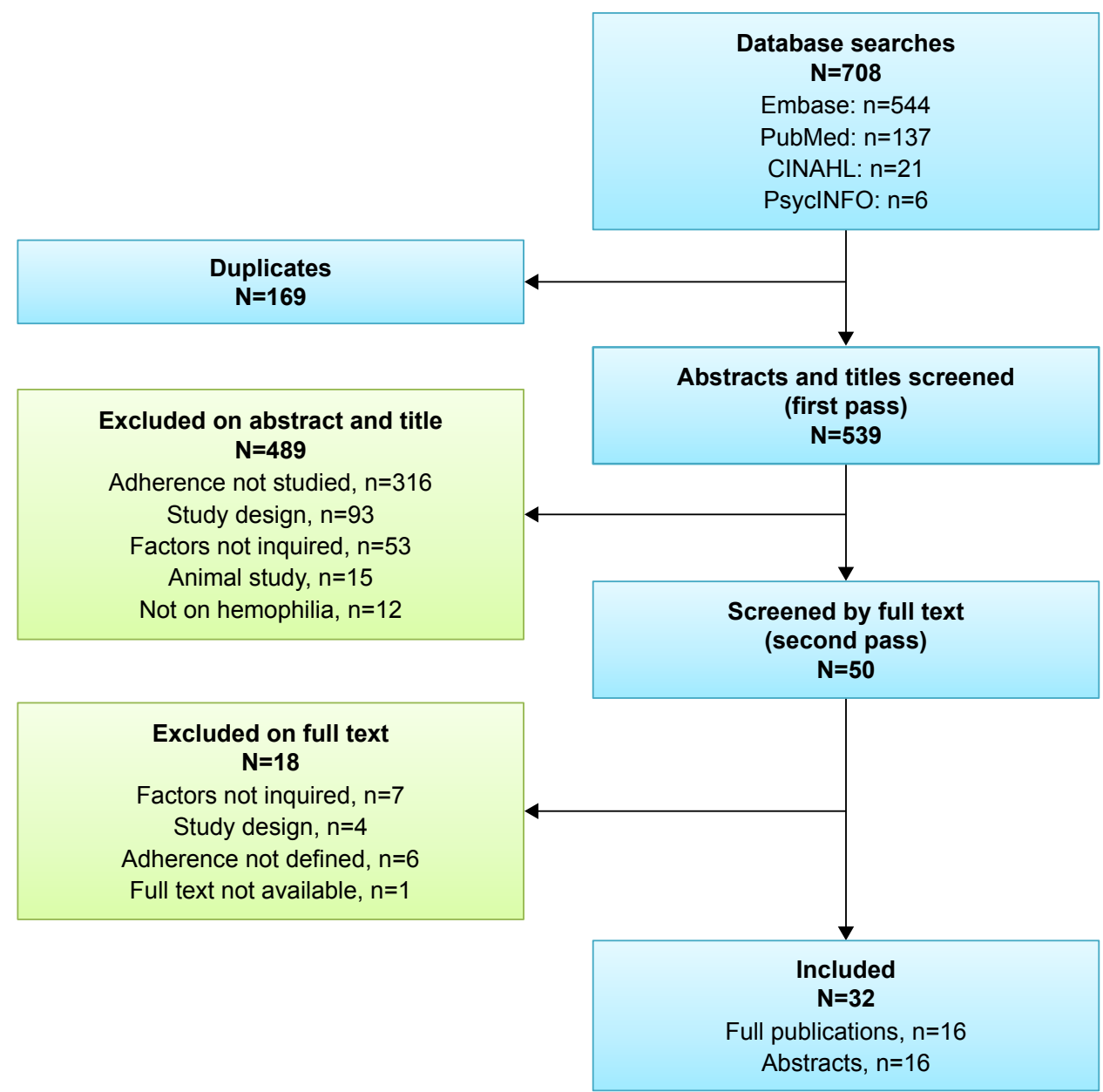

Figure S2 Flow diagram of retrieved studies in the review of factors of adherence in hemophilia patients treated with prophylaxis, $20 \mathrm{II}-20 \mathrm{I7}$.

Patient Preference and Adherence

\section{Publish your work in this journal}

Patient Preference and Adherence is an international, peer-reviewed, open access journal that focuses on the growing importance of patient preference and adherence throughout the therapeutic continuum. Patient satisfaction, acceptability, quality of life, compliance, persistence and their role in developing new therapeutic modalities and compounds to optimize clinical outcomes for existing disease states are major areas of interest for the journal. This journal has been accepted for indexing on PubMed Central. The manuscript management system is completely online and includes a very quick and fair peer-review system, which is all easy to use. Visit http://www. dovepress.com/testimonials.php to read real quotes from published authors.

Submit your manuscript here: http://www.dovepress.com/patient-preference-and-adherence-journal 